DEVELOPMENT OF AN INERT CERAMIC ANODE TO REDUCE ENERGY CONSUMPTION IN MAGNESIUM PRODUCTION

Final Report

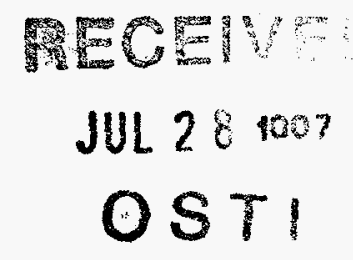

June 1997

Work Performed Under Contract No. FC07-91ID13133

For

U.S. Department of Energy

Assistant Secretary for

Energy Efficiency and Renewable Energy

Washington, DC

By

The Dow Chemical Company

Midland, MI 
DOE/ID/13133

Distribution Category UC-1400

\title{
DEVELOPMENT OF AN INERT CERAMIC ANODE \\ TO REDUCE ENERGY CONSUMPTION \\ IN MAGNESIUM PRODUCTION
}

Final Report

June 1997

Work Performed Under Contract No. FC07-91ID13133

\author{
Prepared for the \\ U.S. Department of Energy \\ Assistant Secretary for \\ Energy Efficiency and Renewable Energy \\ Washington, DC
}

Prepared by

The Dow Chemical Company

1776 Building

Midland, MI 48674-1776 


\section{DISCLAMMERR}

Portions of this document may be illegible in electronic image products. Images are produced from the best available original document. 


\section{TABLE OF CONTENTS}

Executive Summary $\quad$............................................................ 5

Introduction

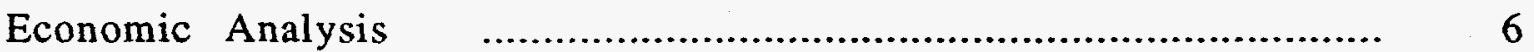

Ceramic Shell Development ….................................................... 10

Slip Casting

Raw Materials $\quad$.................................................. 12

Slip Preparation......................................................... 13

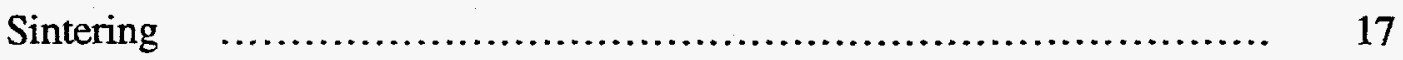

Ceramic Physical Characterization $\quad$......................................... 20

Anode Assembly Development ……....................................... ' 21

Core Material Identification …................................................. 22

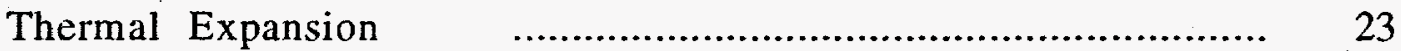

FEA Stress Modeling ……............................................ 25

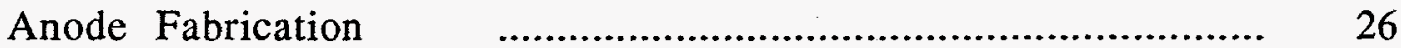

Pre-densified SHS Core Material …………….......................... 27

Bonding of Shell to Core (....................................................... 31

Alloy Precoating $\quad$............................................ 33

Electrical Performance Optimization $\quad$.................................................. 33

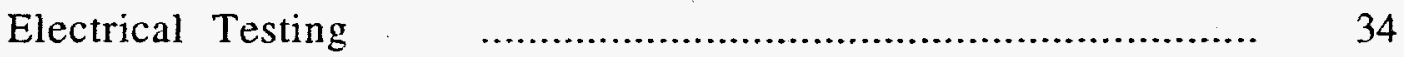

Raw Material Cost Reduction ….................................................. 38

Ceramic Shell Composition Variations …….................................. 38

Material Substitutions …................................................... 39

Anode Design Variations ……………................................ 39

Laboratory Scale Magnesium Cell Testing ………................................. 41

Initial Lifetime Results _................................................. 41

Anode Failure Mode and Proposed Failure Mechanism $\quad$...................... $\quad 43$

Affect of Furnace Atmosphere on Dopant Solubility ......................... 45

Ceramic Quality Impact of Corrosion Failure $\quad$.................................. 47

Short Duration Anode Testing ….......................................... 50

Slip Casting Process Refinements _.......................................... 51 


\section{TABLE OF CONTENTS (cont.)}

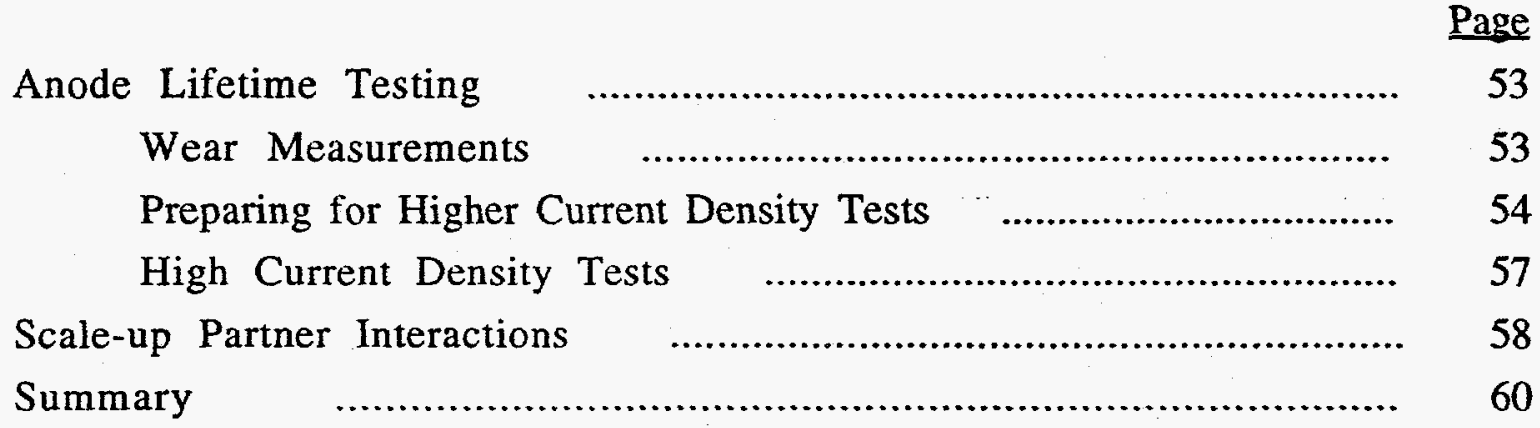

\section{LIST OF FIGURES}

Figure 110 Year Change in Annual Profit Before taxes $\quad$................... 9

Figure 210 Year Change in Cumulative NPV $\quad . . . . . . . . . . . . . . . . . . . . . . \quad 10$

Figure 3 Sketch of Slip Casting Process $\quad$............................... 12

Figure 4 Deflocculation Repose $\quad$....................................... 15

Figure 5 Viscosity difference between $\mathrm{Ta}$ and $\mathrm{Nb} \quad \ldots \ldots \ldots \ldots \ldots \ldots \ldots . . . . . . . . .16$

Figure 6 Effect of Solids Loading on Slip Viscosity $\quad$....................... 17

Figure 7 Density vs. Temperature for sintering of $\mathrm{TiO}_{2} \quad \ldots . . . . . . . . . . . . . . \quad 18$

Figure 8 Microstructure of Sintered 3 mole $\% \mathrm{Nb}_{2} \mathrm{O}_{5}$ doped $\mathrm{TiO}_{2} \quad \ldots \ldots . \quad 19$

Figure 9 Optimized Microstructure of Sintered 3 mole $\% \mathrm{Nb}_{2} \mathrm{O}_{5}$

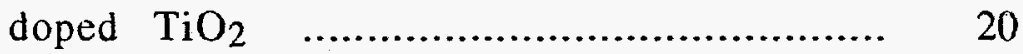

Figure 10 Thermal Expansion of Anode Components $\quad$.................. 23

Figure 11 Thermal Cycling Effect on Thermal Expansion $\quad$.................. 24

Figure 12 Thermal Cycling Effect on Thermal Expansion Comparison . ... 24

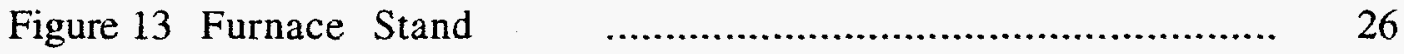

Figure 14 Schematic View of a SHS Reaction $\quad$............................ 29

Figure 15 Sketch of Lab Scale Anode Using SHS Core Material $\quad$......... $\quad 30$

Figure 16 Thermal Expansion of Shell and Core Materials $\quad$................ 31

Figure 17 Micrographs of Shell/Core Bonding Experiments $\quad$............... 32

Figure 18 Sketch of High Temperature Resistivity Testing Apparatus $\quad . . . . \quad 35$

Figure 19 Resistivity vs. Temperature Graph $\quad$............................. 36

Figure 20 Anode Sketch with Embedded Conduction Rod $\quad$............... 37

Figure 21 Electrical Resistivity vs. Dopant Concentration $\quad$................... $\quad 40$ 


\section{LIST OF FIGURES (cont.)}

Figure 22 Sketch of Laboratory Scale Electrolytic Cell $\quad$....................... $\quad 42$

Figure 23 Proposed Anode Failure Mechanism $\quad$.......................... 44

Figure 24 Micrograph of the ceramic shell fabricated in a

reducing atmosphere $\quad$............................... 46

Figure 25 Micrograph of the ceramic shell fabricated in a

air atmosphere $\quad$................................... 46

Figure 26 Series of micrographs showing corrosion $\quad$..................... 49

Figure 27 Cross-section of pitting type corrosion $\quad$.......................... 50

Figure 28 Micrograph of Pinhole Defect $\quad$.................................. 48

Figure 29 Micrograph of a healed greenware crack $\quad \ldots . . . . . . . . . . . . . . . . ., \quad 50$

Figure 30 Production magnesium cell sketch ............................ 56

Figure 31 Full scale anode sketch $\quad$....................................... 58

\section{LIST OF TABLES}

Table I Economic analysis of ceramic anode implementation $\quad . . . . . . . .8$

Table II Deflocculant performance $\quad$....................................... 15

Table III Ceramic physical properties $\quad$.................................... 21

Table IV Anode wear data $\quad$.............................................. 54 


\section{Executive Summary}

The objective of this work has been to develop an inert, dimensionally stable anode for the production of magnesium in electrolytic reduction cells presently used by Dow Chemical. This project was partially funded $(80 \%)$ by the U.S. Department of Energy, Office of Industrial Processes, Conservation and Renewable Technology. A stable anode would allow optimization of the spacing between anode and cathode yielding energy savings of approximately $2 \mathrm{~kW}$-hr per pound of magnesium produced. In addition, the currently used graphite anodes are consumed during electrolysis at a cost of several million dollars every year. There is also considerable projected labor savings from the elimination of the need to reposition the anodes to maintain the anode's electrical efficiency. Not having to adjust the anode would allow better sealing at the furnace/anode interface for substantial environmental benefits. To make laboratory scale anodes, a formulation resulting in a semiconductive ceramic $\left(\mathrm{TiO}_{2}+\mathrm{Ta}^{+5}\right.$ and $\left.\mathrm{TiO}_{2}+\mathrm{Nb}^{+5}\right)$ material is formed as a thin walled closed end tube by slip casting and sintering. The tube is then filled with a metal-ceramic composite matched in thermal expansion and serving as the primary current carrier. The anodes are tested in laboratory-scale magnesium cells.

The testing goal for Phase II of the cooperative agreement was to demonstrate six anodes surviving a 30 day test lifetime with acceptable wear rates and electrical performance in a laboratory scale magnesium cell test. In order to accomplish this goal, state of the art slip casting techniques were used and advanced in the pursuit of a virtually flaw free ceramic anode shell. Novel core materials were also invented to allow for the complete, crack free fabrication of the laboratory scale anode. Two successive anodes were tested and exceeded the 30 day cell lifetime goal with excellent wear characteristics. Unfortunately, a notification that the Government portion for Phase III funding would not be available shifted the testing emphasis to more aggressive laboratory tests to evaluate the technical risk associated with continuing the anode replacement project without Government funding. The more aggressive testing revealed that the ceramic anode had a rather narrow operating region. This lack of robustness of the dimensionally stable ceramic anode resulted in the Dow Chemical Company's Magnesium Business making the decision not to continue the project without continued Government support. 


\section{Introduction and Background}

The objective of this work is to develop a dimensionally stable ceramic anode for production of magnesium metal in electrolytic cells, replacing the graphite anodes currently used by The Dow Chemical Company magnesium business. The implementation of a dimensionally stable anode would have significant financial impact by improving the electrical efficiency of the electrolytic process. Additional savings will also be realized by a reduction in labor costs currently needed to position and feed the graphite anodes which have significant wear rates due to the corrosive nature of the electrolytic process. Not having to adjust the anode would also allow better sealing at the furnace/anode interface for substantial environmental benefits.

Because of the energy savings potential of this work, this project is being partially funded ( $80 \%$ ) by the U.S. Department of Energy, Office of Industrial Processes, Conservation and Renewable Technology. The work is based on compositional and design technology for a ceramic anode developed in the former Central Research Inorganic Laboratory 1 . The approach selected is to use a ceramic semiconductor tube as the material to interface with the bath and gaseous atmosphere in the cell. To compensate for the ceramic's higher resistivity compared to graphite, the ceramic is to be prepared as a thin hollow shell (tube) closed at one end. The ceramic shell is then to be filled with a high conductivity, both electrical and thermal, core. The core is to contain a metal component that provides the high conductivity. To compensate for the high thermal expansion of the metal, the core contains ceramic particles in sufficient quantity to minimize the thermally induced stresses between the shell and core. Thus the anode is to be a ceramic tube filled with a metal-ceramic composite core.

This report encompasses the work on developing a dimensionally stable anode during the period of 1/1/91 through 12/31/96.

\section{Economic Analysis}

An economic analysis is valuable tool when making any business decision. The following is an economic analysis targeting the potential financial impact of implementing a dimensionally stable ceramic anode into Dow's magnesium processes. The analysis is 
reported in the form of change in net present value (NPV), and not in absolute NPV, numbers which have components that are Dow propriety information.

The basis for the model is that the phase III of the Government cooperative agreement would begin in January, 1997 and would concluded successfully in December, 1999. The dimensionally stable anode technology would then be implemented in stages in Dow's production facility and reach full conversion by December, 2004. The model numbers reflect the staged implementation of the replacement anodes at the $10 \%$ replacement level of the production anodes in 1999. In 2001, a total of $25 \%$ of the production anodes are the new ceramic anodes. Between 2003 and 2005, the remaining graphite anodes are replaced at $25 \%$ a year rate. For this analysis, it was assumed that the implementation of the replacement ceramic anodes would not have an effect, neither positive nor negative, on the quality of the magnesium produced or on the production rate. The replacement project would only effect the electrical efficiency and thus the utilities cost, the operating labor, and small fixed capital for implementation. No dollar value is assigned to the positive impact on the environmental issues. The cost for the ceramic anode has been estimated at the cost of the equivalent graphite that is consumed for each anode site over a $21 / 2$ year period (the designed lifetime of a ceramic anode). This anode cost estimate has been validated by our scale-up partner. The electrical efficiency of the ceramic anode is assumed to be equivalent to the graphite anodes currently used. The electrical cost used for this analysis was 3.5 cents per $\mathrm{kW}$-hr. The electrical saving achieved by the ceramic anode is based solely on its dimensionally stability. This energy saving is realized in the economic model as a function of the percent of anode implementation. A $10.75 \%$ cost of capital was used in the model.

Table I presents the economic value of implementation of a dimensionally stable ceramic anode over a ten year span.

This table reveals that at ten years, the annual net present value (NPV) of the anode replacement project is over $\$ 12 \mathrm{MM}$ with a cumulative NPV of almost $\$ 60 \mathrm{MM}$. The increase in annual profit before taxes is $\$ 21 \mathrm{MM}$. The major portion of this savings is the $\sim 15 \mathrm{MM}$ savings from the increased electrical efficiency of the dimensionally stable ceramic anodes. 
Table I. Economic Analysis Ceramic Anode Implementation

\begin{tabular}{|c|c|c|c|c|c|c|c|c|c|c|c|}
\hline \multirow{2}{*}{\multicolumn{12}{|c|}{ Production Mix }} \\
\hline & & & & & & & & & & & \\
\hline $\begin{array}{l}\text { Mag Produced with Graphite Anodes } \\
\text { Mag Produced with Ceramlc Anodes }\end{array}$ & $\begin{array}{r}100 \% \\
0 \%\end{array}$ & $\begin{array}{r}100 \% \\
0 \%\end{array}$ & $\begin{array}{l}90 \% \\
10 \%\end{array}$ & $\begin{array}{l}90 \% \\
10 \%\end{array}$ & $\begin{array}{l}75 \% \\
25 \%\end{array}$ & $\begin{array}{l}75 \% \\
25 \%\end{array}$ & $\begin{array}{l}50 \% \\
50 \%\end{array}$ & $\begin{array}{l}25 \% \\
75 \%\end{array}$ & $\begin{array}{r}0 \% \\
100 \%\end{array}$ & $\begin{array}{r}0 \% \\
100 \%\end{array}$ & $\begin{array}{r}0 \% \\
100 \%\end{array}$ \\
\hline $\begin{array}{l}\text { Anode Cost } \\
\text { Uttilties \& Operating Labor } \\
\text { Depreciation } \\
\text { TOTAL MFG COST DELTA }\end{array}$ & $\begin{array}{r}0 \\
0 \\
80 \\
80\end{array}$ & $\begin{array}{r}0 \\
0 \\
100 \\
100\end{array}$ & $\begin{array}{r}0 \\
-2.070 \\
260 \\
-1.810\end{array}$ & $\begin{array}{r}0 \\
-2,070 \\
0 \\
-2070\end{array}$ & $\begin{array}{r}0 \\
-5,280 \\
40 \\
-5,240\end{array}$ & $\begin{array}{r}0 \\
-5,280 \\
-0 \\
-5,280\end{array}$ & $\begin{array}{r}0 \\
-10,560 \\
40 \\
-10,520\end{array}$ & $\begin{array}{r}0 \\
-14,235 \\
40 \\
-74,195\end{array}$ & $\begin{array}{r}0 \\
-21.015 \\
0 \\
-21,015\end{array}$ & $\begin{array}{r}0 \\
-21,015 \\
0 \\
-21,015\end{array}$ & $\begin{array}{r}0 \\
-21.015 \\
0 \\
-21.015\end{array}$ \\
\hline \multicolumn{12}{|l|}{ Capital } \\
\hline $\begin{array}{l}\text { R\&D - Small } \\
\text { MFG - Small } \\
\text { Total Flxed Capital Delta }\end{array}$ & $\begin{array}{r}150 \\
50 \\
200\end{array}$ & $\begin{array}{r}150 \\
100 \\
250\end{array}$ & $\begin{array}{r}150 \\
500 \\
650\end{array}$ & $\begin{array}{l}0 \\
0 \\
0\end{array}$ & $\begin{array}{r}0 \\
100 \\
100\end{array}$ & $\begin{array}{l}0 \\
0 \\
0\end{array}$ & $\begin{array}{r}0 \\
100 \\
100\end{array}$ & $\begin{array}{r}0 \\
100 \\
100\end{array}$ & $\begin{array}{l}0 \\
0 \\
0\end{array}$ & $\begin{array}{l}0 \\
0 \\
0\end{array}$ & $\begin{array}{l}0 \\
0 \\
0\end{array}$ \\
\hline Book ValueDelta (M\$) & 200 & 250 & 640 & 640 & 700 & 700 & 760 & 820 & 820 & 820 & 820 \\
\hline
\end{tabular}

\section{Cash Flow Delta Summary}

\section{Profit Before Tax (PBT) \\ Tax \\ Profit After Tax (NOPAT) \\ Annual Cash Flow \\ Cumulative Cash}

Cumulative Economic Profit

Annual NPV Delta

Cumulative NPV Delta

$\begin{array}{rr}-80 & -100 \\ -30 & -38 \\ -50 & -62 \\ -170 & -212 \\ -170 & -2 \\ -71 & -89 \\ -71 & -88\end{array}$

$\begin{array}{rr}-100 & 18 \\ -38 & 688 \\ -62 & 11 \\ -212 & 732 \\ -212 & 520 \\ -88 & 105 \\ -88 & 967\end{array}$

$\begin{array}{ll}-161 & -201 \\ -161 & -201\end{array}$

$\begin{array}{rrr}1810 & 2070 & 5240 \\ 688 & 787 & 1991 \\ 1122 & 1283 & 3249 \\ 732 & 1283 & 3189 \\ 520 & 1283 & 4472 \\ 1055 & 1216 & 3175 \\ 967 & 2183 & 5358 \\ & & \\ & & \\ 694 & 1,217 & 3,023 \\ 493 & 1,710 & 4,733\end{array}$

$\begin{array}{rr}5280 & 105 \\ 2006 & 3 \\ 3274 & 6 \\ 3274 & 6 \\ 7746 & 1420 \\ 3200 & 6 \\ 8558 & 1500 \\ & \\ & \\ 3,104 & 6,127 \\ 7,837 & 13,964\end{array}$

$\begin{array}{rr}10520 & 14195 \\ 3998 & 5594 \\ 6522 & 8801 \\ 6462 & 874 \\ 14208 & 2294 \\ 6443 & 8715 \\ 15001 & 23716\end{array}$

$$
\begin{array}{r}
14195 \\
5394 \\
8801 \\
8741 \\
22949 \\
8715 \\
23716
\end{array}
$$

4195
5394
8801
8741
22949
8715
23716

$$
\begin{array}{r}
210 \\
7986 \\
13029 \\
13029 \\
3597 \\
129 \\
36659
\end{array}
$$

21015
7986
13029
13029
35978
12943
36659

21015

7986

13029

13029

49008

12943
49602

8,287
22,252

12,353
34,605

12,353

46,959

59,312 
More information can be extracted from this model by performing a sensitivity analysis. The following model variables are explored in the sensitivity analysis:

- $\quad 1 / 2$ cent $\mathrm{kW}-\mathrm{hr}$ increase in cost of electricity

- $\quad 1 / 2$ cent $\mathrm{kW}-\mathrm{hr}$ decrease in cost of electricity

- $10 \%$ improvement in electrical performance with respect to graphite anodes

- $10 \%$ reduction in electrical performance with respect to graphite anodes

- $10 \%$ decrease in replacement anode price

- $10 \%$ increase in replacement anode price

- Loss of Government funding for Phase III

The impact of these variables on the annual profit and the cumulative net present value after ten years is presented in figures 1 and 2 .

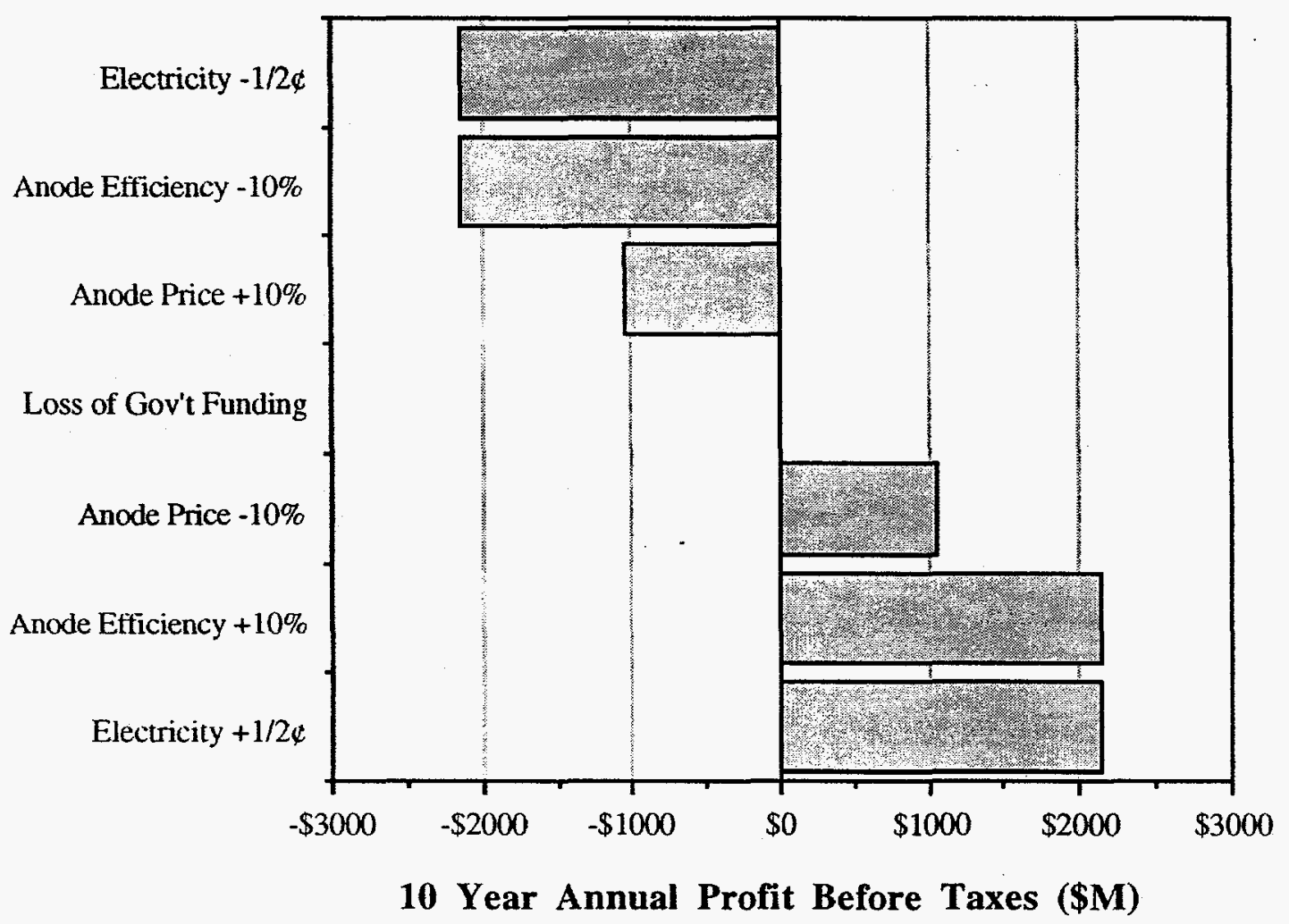

Figure 1, 10 year charge in annual profit before taxes sensitivity analysis. 


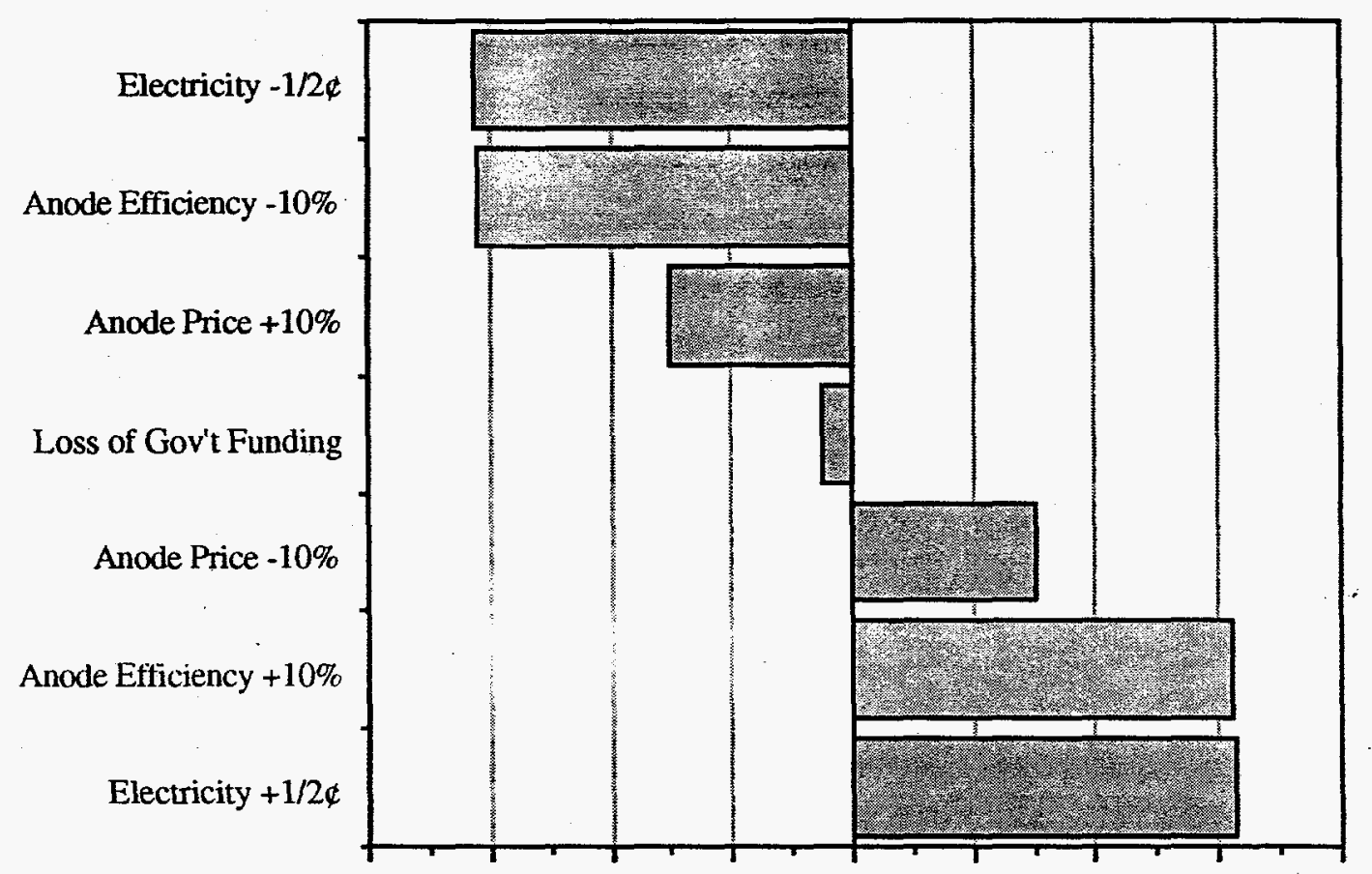

Figure 2,10 year charge in cumulative NPV sensitivity analysis.

The two figures reveal that the change in cost of electricity and change in the electrical efticiency of the ceramic anode have the largest impact on both cumulative net present value and profit before taxes. The smallest impact on these economic indicators was the loss of Government funding for Phase $\mathrm{II}$ of the cooperative agreement. This small number arises from the analysis being evaluated at the 10 year interval which has the effect of deemphasizing initial capital costs associated with the project implementation.

\section{Ceramic Shell Development}

The concept of making a dimensionally stable anode for magnesium production has a long history at the Dow Chemical Company 1 . The initial research performed on this technology identified some key issues faced by a ceramic anode. The first stems from the fact that most ceramics are electrically insulating. Obviously, for an electrolytic application such as used in magnesium production, this severely limits the choice of ceramic to one that has some electrical carrying capability. Even the most electrically conductive ceramics are simply not electrically efficient enough to be used as a electrode. Thus, a ceramic closed- 
end tube must be fabricated and then filled with a highly conducting core to make an effective dimensionally stable anode. For the ceramic portion of this anode, the initial work performed by Dow Chemical identified titanium dioxide doped with tantalum pentoxide as a material that has both corrosion resistance to the molten salts in the magnesium electrolytic process and acceptable electrical semiconductivity. However, this initial research ran into insurmountable fabrication challenges when making the ceramic shell and then filling the shell with a conductive core. These fabrication problems, specifically the cracking of the ceramic shell, led to the work being discontinued. It is believed that the application of contemporary ceramic science and engineering methodologies can overcome these difficulties.

The initial ceramic anode research focused on isopressing a closed end ceramic tube. This process resulted in a ceramic article that had numerous flaws that were then exploited to cause failure when tested in the magnesium electrolytic process. The approach that this research takes is to "slip cast" the ceramic part. Slip casting is a ceramic forming process that is nicely suited to the production of thin walled ceramic parts and also is relatively easy to scale-up to production sizes.

\section{Slip Casting}

Slip casting is a classic ceramic forming process. The basic slip casting process has just a few steps. The first step is to suspend the ceramic particles in a liquid medium (most often water). This ceramic/liquid mixture is called the 'slip'. From a simplified view, the more stable the slip is the more uniform and flaw free the resultant ceramic part will be. This slip is then carefully poured into a properly prepared plaster mold. A lot of the 'art' of slip casting deals with the plaster mold preparation and can dramatically increase or decrease the quality of the resultant ceramic part. The plaster mold has a certain degree of porosity that is one of the mold making design variables that directly effect the ceramic part's casting time, density gradients, and surface texture. This porosity serves to draw the water out of the slip leaving behind a 'cake' on the plaster wall. When this cake gets to a designated thickness, the remaining slip is pour out of the mold. The cake is then allowed to dry in a very controlled manner to avoid any cracking of the cake. This cake is then removed from the plaster mold and dried further. This dried slip cast cake is called 'greenware'. This greenware can then be sintered or densified into a hard, dense ceramic part. Figure 3 shows a sketch of the slip casting mold used in casting the laboratory scale ceramic anode. 


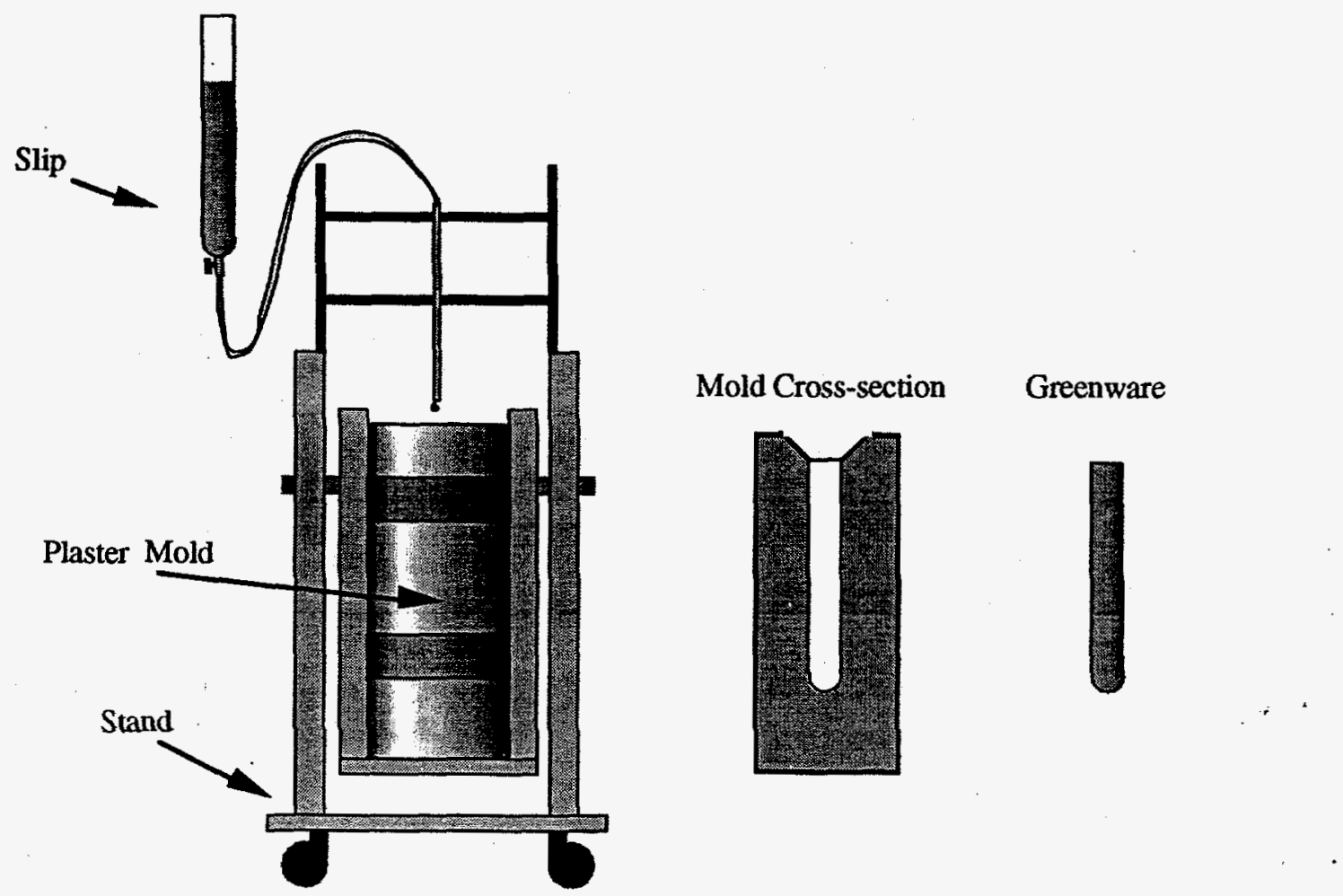

Figure 3, Sketch of the slip casting mold used in casting the laboratory scale ceramic anode

The following sections describe the particulars of identifying the raw materials, slip formulation and optimization, and sintering of the laboratory scale ceramic anode.

\section{Raw Materials}

The criteria for selecting the raw materials for fabricating the ceramic shell were as follows:

- Corrosion resistance to the magnesium cells molten salt environment.

- Electrical properties (electrically conducting or semiconducting)

- Available in commercial quantities.

- High in purity ( $\geq 99.5 \%$ ).

- Suitable for use in the process of slip casting of greenware in gypsum plaster molds.

In Dow's earlier research into dimensionally stable ceramic anodes, numerous ceramic materials were tested for corrosion resistance to the magnesium cells molten salt environment and electrical conductivity 1 . The results of this study showed that titanium dioxide $\left(\mathrm{TiO}_{2}\right)$ had good corrosion resistance, but more importantly, became electrically semiconducting when doped with 1-5 mole \% tantalum pentoxide ( $\mathrm{Ta}_{2} \mathrm{O}_{5}$ ). This doped titanium dioxide was used in Phase $\mathrm{I}$ and part 
of Phase II of the cooperative agreement. However, a preliminary economic analysis pointed out that the high cost of tantalum pentoxide, even at the low doping levels, would add considerably to the cost of the final anode. Niobium pentoxide $\left(\mathrm{Nb}_{2} \mathrm{O}_{5}\right)$ was identified as a potential replacement for tantalum pentoxide due to its similar electronic valence characteristics and also it's significantly lower cost on a molar basis. When $\mathrm{Nb}_{2} \mathrm{O}_{5}$ was used as a dopant to titania, it was found that the resultant ceramic material was also semiconducting with a very similar if not slightly more conducting in nature. Thus, the change was made with $\mathrm{Nb}_{2} \mathrm{O}_{5}$ replacing $\mathrm{Ta}_{2} \mathrm{O}_{5}$ as the minor component of the ceramic used for the ceramic shell.

Titanium dioxide (titania) meets the third criteria with its wide commercial use base. The major uses for titania is as a pigment in products such as paints, plastics and pharmaceuticals. These pigments often have additives. Since titania is the major component of the semiconducting material that is doped with either the $\mathrm{Ta}_{2} \mathrm{O}_{5}$ or $\mathrm{Nb}_{2} \mathrm{O}_{5}$ material, the availability of titania is the dominant factor.

The $\mathrm{TiO}_{2}$ selected having the needed purity was from TAM Ceramics, Inc. and is their TICONTM grade HP 59030. The $\mathrm{Ta}_{2} \mathrm{O}_{5}$ powder selected was from Hermann C. Starck Berlin, and is their standard optical grade. The $\mathrm{Nb}_{2} \mathrm{O}_{5}$ powder selected was from Kronos, inc. and is their high purity, ceramic grade.

All of the materials selected meet the third and forth criteria listed above. In the next section are described the procedures used to make them meet the fifth one. The titania is within the "typical properties" as listed by the supplier for surface area but the particle size, based on the $\mathrm{D}_{50}$, is somewhat higher than the top of the $1-5 \mu \mathrm{m}$ range listed. Starck's tantalum pentoxide is supplied with a nominal particle size of $90 \%$ minus 325 mesh $(44 \mu \mathrm{m})$ and is somewhat larger than that with a measured D90 of $50 \mu \mathrm{m}$. Its surface area is low as expected with the large particle size. The Kronos material has a very similar size distribution to the Starck material. All of the materials are too large in particle size to make good casting slips without grinding to a $D_{90} \leq 2 \mu \mathrm{m}$.

\section{Slip Preparation}

Dispersion of the powder within a slip is critical to the uniformity to the resultant ceramic part. Dispersion response was examined by measuring the viscosity as a function of surfactant addition (deflocculation curves). The viscosity was measured with a Brookfield rotating disc viscometer. The slip $\mathrm{pH}$ was monitored during the surfactant addition. In addition, the slips were examined for any foaming while these deflocculation curves were being constructed.

Surfactant performance during attrition milling was examined by measuring the particle size distribution of a 40 volume $\% \mathrm{TiO}_{2}$ slip after 11 hours of attrition milling at 
$200 \mathrm{rpm}$. Due to the coarse nature of starting powder, a 40 volume \% suspension could not be obtained (due to dilatant flow) prior to attrition milling. For this reason, the water was added to the attritor first, and the powder was added slowly while the attritor was running. The attrition mill size was 1 quart. The milling media was $5 \mathrm{~mm}$ yttria stabilized zirconia balls. The media was added in sufficient amount to just cover the top of the attritor blade. The formulation was sized so it was sufficient to just cover the media during attrition $(\approx 350 \mathrm{ml})$. Further information on deflocculant performance during attrition was gained by measuring the Brookfield viscosity after removing the slip from the attrition mill.

Deflocculant requirements are:

1) Maximum powder dispersion.

2) Minimal degradation during attrition milling.

3) Deflocculate in mid to high $\mathrm{pH}$ range.

4) Low foaming.

5) Clean, efficient burnout.

6) Ammonium based (for conductivity requirements).

Requirement 2) is necessary because these powders must be attrition milled due to the coarseness of their particle size. Deflocculation in the mid to high $\mathrm{pH}$ range is preferable to reduce plaster mold wear. Ammonium based dispersants were used because they do not leave a cationic residue which is capable of affecting conductivity measurements. Requirements 1), 4), and 5) are standard for a normal slip casting operation.

Deflocculation curves similar to Figure 4 were constructed for a number of different dispersants. The performance of each of the surfactants is summarized in Table II. It can be seen from the table that Darvan C, Darvan $821 \mathrm{~A}$, and $\mathrm{pH}$ adjusted citric acid seem to promote good $\mathrm{TiO}_{2}$ powder dispersion. Other dispersants either were not as powerful, or they dispersed in a low $\mathrm{pH}$ range and/or foamed substantially.

The Darvan C, Darvan 821A, and $\mathrm{pH}$ adjusted citric acid surfactant systems were selected for further evaluation based on their superior properties. It was found that the viscosity of the slips deflocculated with the Darvans were at least an order of magnitude greater than the slip dispersed with $\mathrm{pH}$-adjusted citric acid. It was also seen by comparing the D90 values that the particle size distributions of the slips deflocculated with the Darvans were significantly coarser creating a less desirable slip than the slip deflocculated with $\mathrm{pH}$ adjusted citric acid. 
Table II. Summary of Deflocculant Performance

SURFACTANT

Darvan C

Darvan $821 \mathrm{~A}$

Colloid 111M

Ammonium Citrate

Nalco CX2209

Ammonium Hydroxide

Citric Acid

\section{PERFORMANCE}

Excellent, dispersed in mid $\mathrm{pH}$ range

Excellent, dispersed in mid $\mathrm{pH}$ range

Excellent, but foamed substantially

Fair, dispersed in low $\mathrm{pH}$ range

Good, but foamed substantially

Fair, dispersed in mid to high $\mathrm{pH}$ range

Poor, low $\mathrm{pH}$, did not disperse

$\mathrm{pH}$-adjusted Citric Acid $\left(\mathrm{NH}_{4} \mathrm{OH}\right)$ Excellent, dispersed in mid $\mathrm{pH}$ range

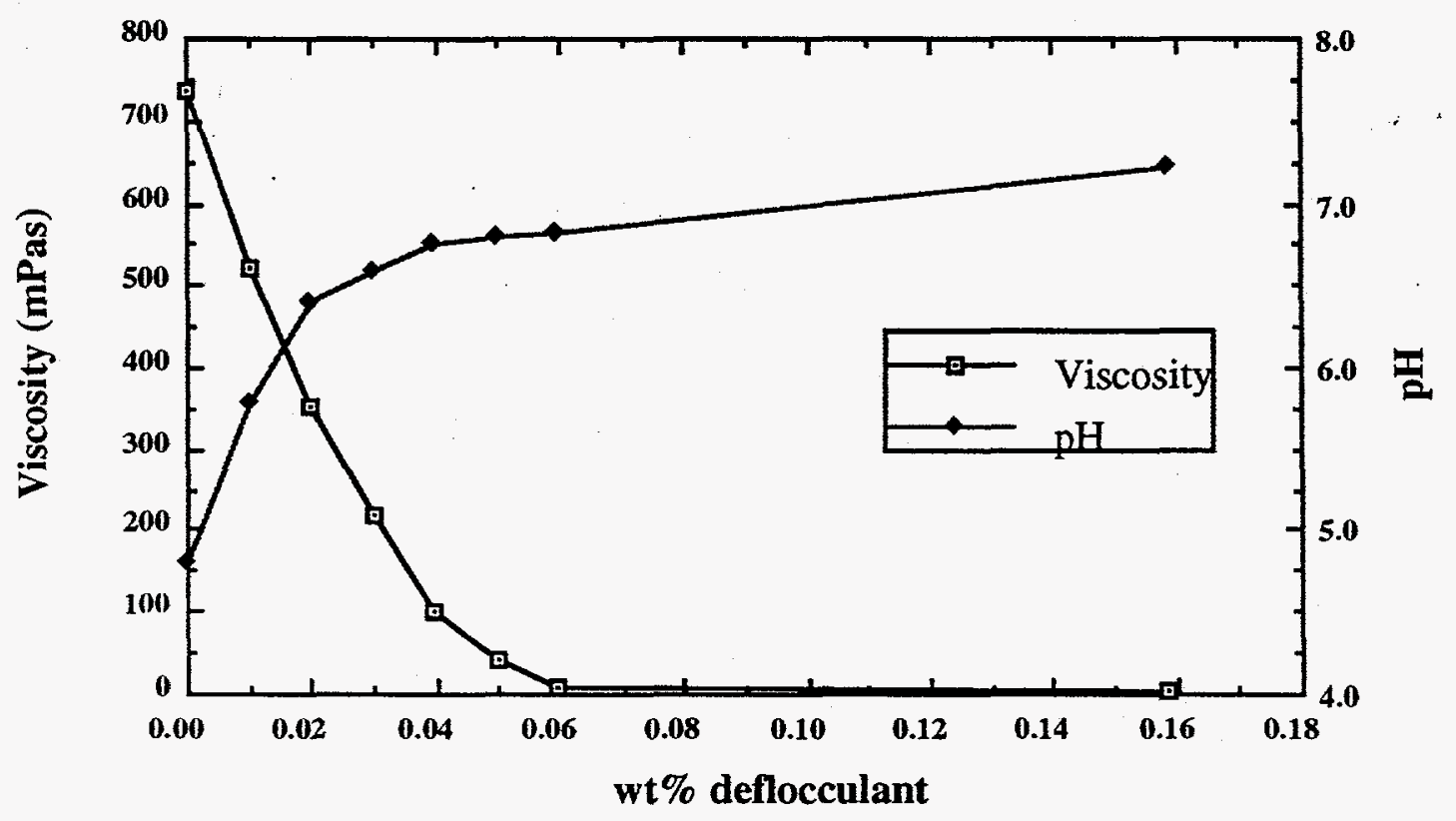

Figure 4, Deflocculation Response of TiO2 to Darvan 821A

The difference in particle size data from slips using different deflocculants can be explained by considering the values for viscosity. If a suspension becomes flocculated during attrition milling (as it is at higher viscosities), a significant percentage of the media impact energy will be used in breaking up flocs, thereby decreasing the available energy available for particle fracture. It seems as though the Darvan surfactants degrade during attrition milling. This behavior has been known to occur for high molecular weight surfactants. Also, the higher slip viscosities will affect the cast adversely by lowering the bulk density of the casting. Thus, $\mathrm{pH}$-adjusted citric acid was used for most of the casting work performed in this program. 
When the change was made from the tantalum doped titania slip to a Niobium slip, the deflocculant selection experiments where repeated. Figure 5 shows the difference in the viscosity between a tantalum and niobium doped slip. Both of these slips where dispersed using the $\mathrm{pH}$ corrected citric acid dispersant which was found to be preferred for the tantalum doped slip. This graph shows that the viscosity of the niobium doped slip is significantly less (approx. -3 times) than the optimized tantalum slip. This reduction in viscosity presents an opportunity to improve the casting density and uniformity by increasing the solids loading of the slip.

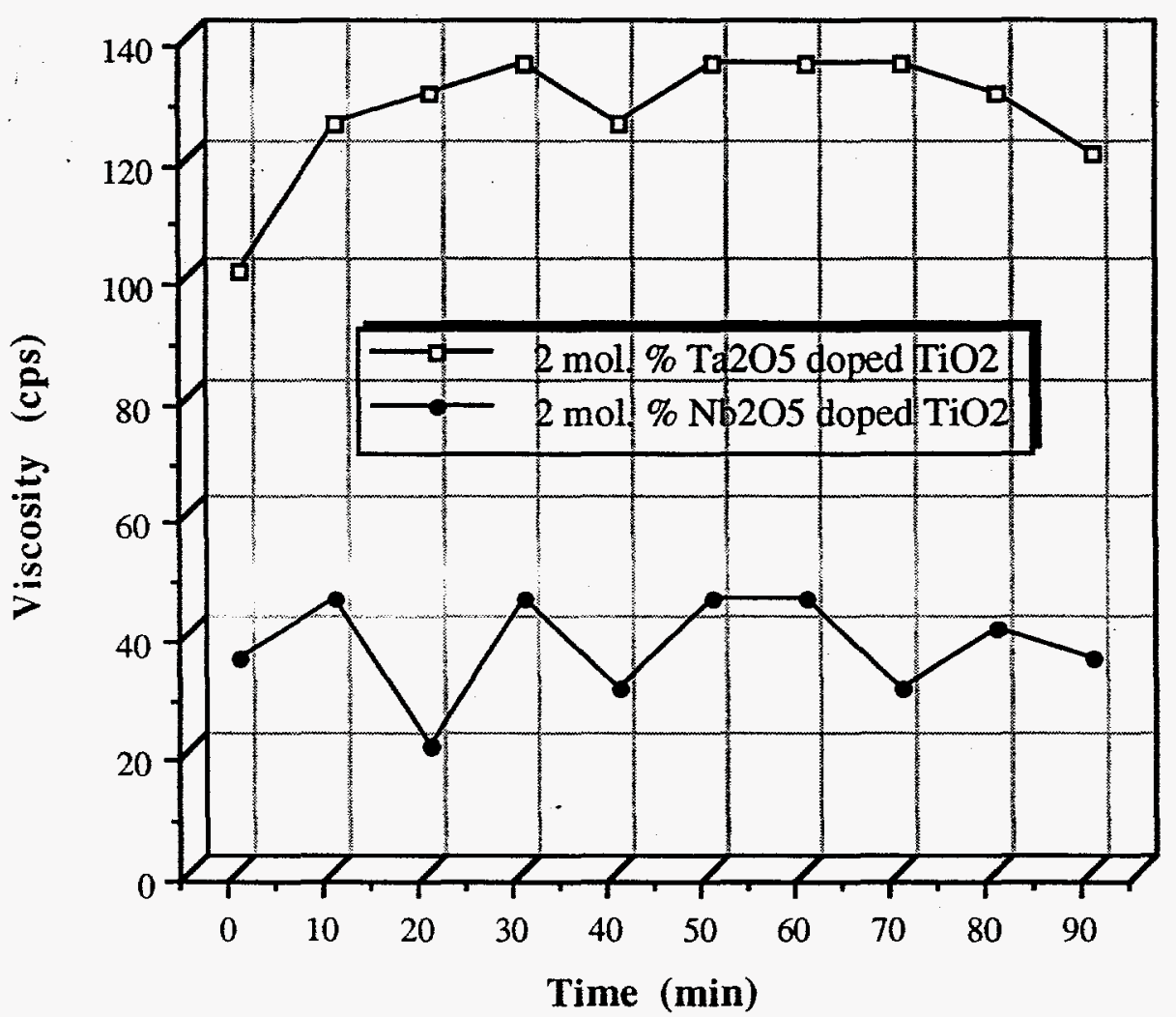

Figure 5, Viscosity difference between tantalum and niobium doped slip

A study was undertaken to evaluate the effect of solids loading on the viscosity. A 60 volume percent solids loaded slip was made making sure that it was milled to the correct particle size. This slip was then mixed with the standard 40 volume percent slip to arrive at the various loadings levels. After tumbling for 30 minutes, the viscosity was measured for 
each slip. Two sets of data were taken for conformation. Figure 6 shows the data from this series of experiments.

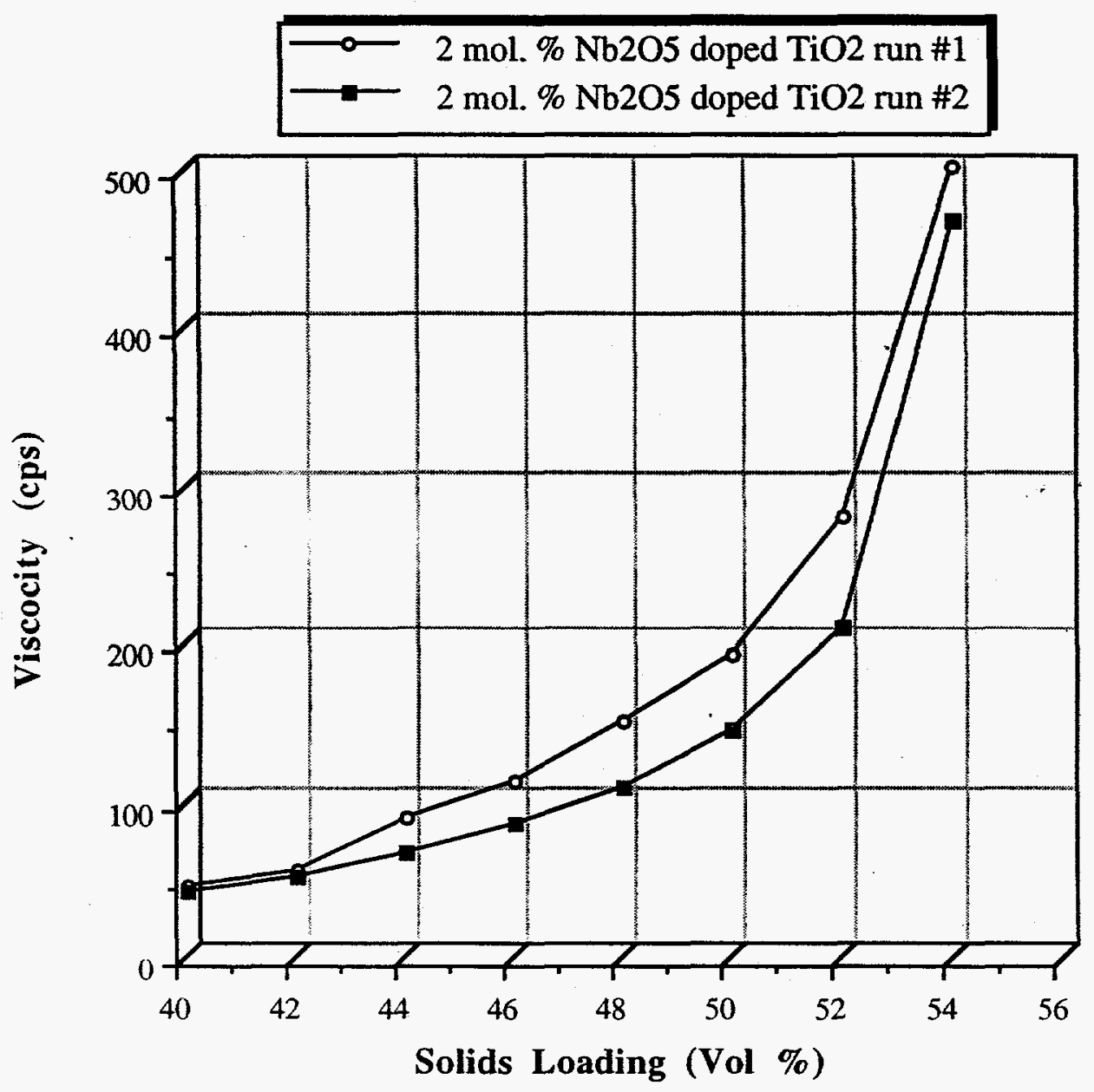

Figure 6, Effect of solids loading on slip viscosity

Based on these viscosity measurements, and the more qualitative observations on handlability of the slip, a solids loading of $48 \%$ was chosen. This higher solids content results in higher cast greenware densities while also reducing the density gradients in the part.

\section{Sintering}

Prior studies ${ }^{2-4}$ of sintering titania have shown high sintered density $(\geq 97 \%$ of theoretical density) being achieved between firing temperatures of $900^{\circ} \mathrm{C}$ and $1550^{\circ} \mathrm{C}$. Sintering shrinkage of titania and titania plus 1 to 5 mole percent tantalum pentoxide was studied using a 
dilatometer (Theta Industries $1600^{\circ} \mathrm{C}$ system) with alumina holder and sensor rod. Titania (11 hr attrition) sintered for two hours at $1200^{\circ}-1250^{\circ} \mathrm{C}$ in air yielded a very acceptable $\geq 99 \%$ dense ceramic. The higher temperature results in a more than doubling of the grain size which can adversely effect the strength of the ceramic.

Figure 7 is a plot of density vs temperature for titania heated at $5{ }^{\circ} \mathrm{C} / \mathrm{min}$ to $1200^{\circ} \mathrm{C}$ and held at that temperature for two hours. By immersion in water (Archimedean method) the bulk density was determined to be $99.0 \%$ of theoretical density (TD).

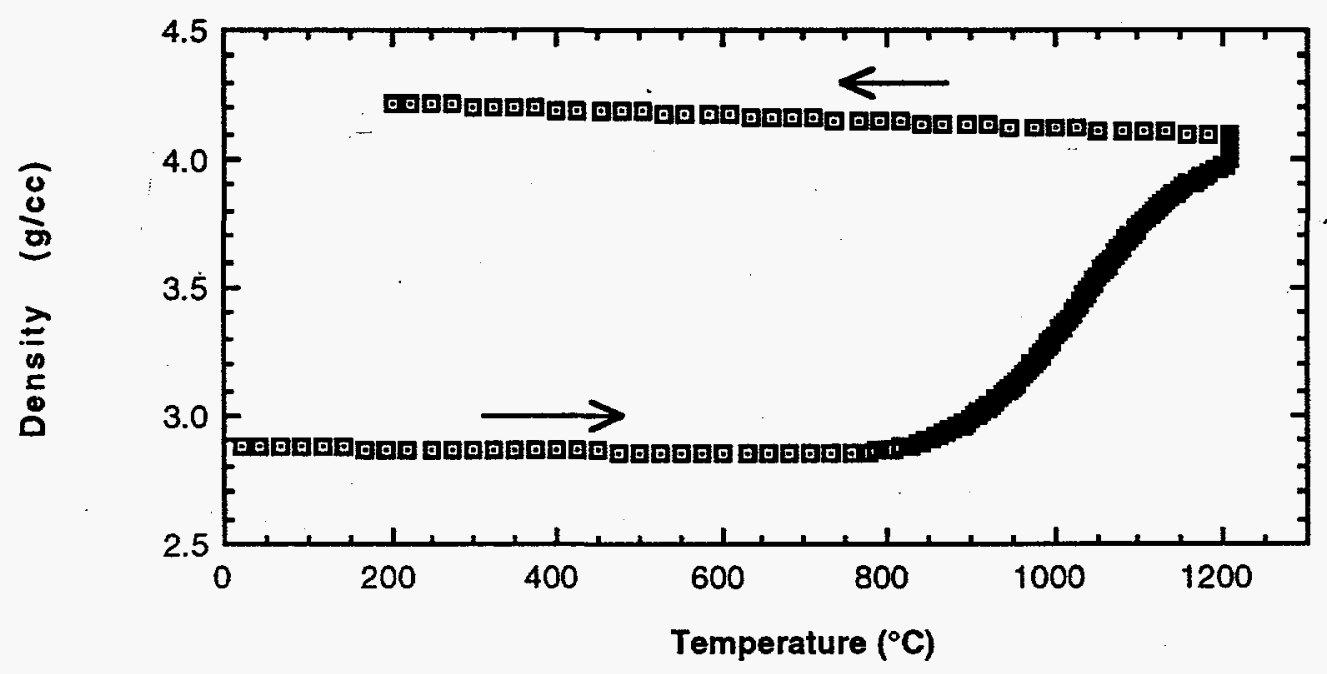

Figure 7, Density versus temperature for the sintering of pure titanium dioxide.

The average grain size was determined to be between 2-3 microns. Increasing the sintering temperature to $1250^{\circ} \mathrm{C}$ results in the larger grain size. The smaller grain size ceramic has the advantage of increased fracture strength and thermal shock resistance but has reduced electrical properties, due to grain boundary resistance, as compared to the larger grain size 4,5 .

The slightly reduced final density of both the tantalum and niobium doped ceramics appear to be caused by a reaction taking place in the early stages of sintering. Figure 8 shows the grain structure of a 3 mole $\% \mathrm{Nb}_{2} \mathrm{O}_{5}$ doped titanium dioxide ceramic sintered with a 3 hour hold at $1200^{\circ} \mathrm{C}$. This ceramic had a final density of $97.6 \%$ of theoretical. The dark spots on the micrograph correspond to voids. These voids are located at the grain boundaries. By simply varying the sintering temperature and time, we were not able to reduce/eliminate these voids. 


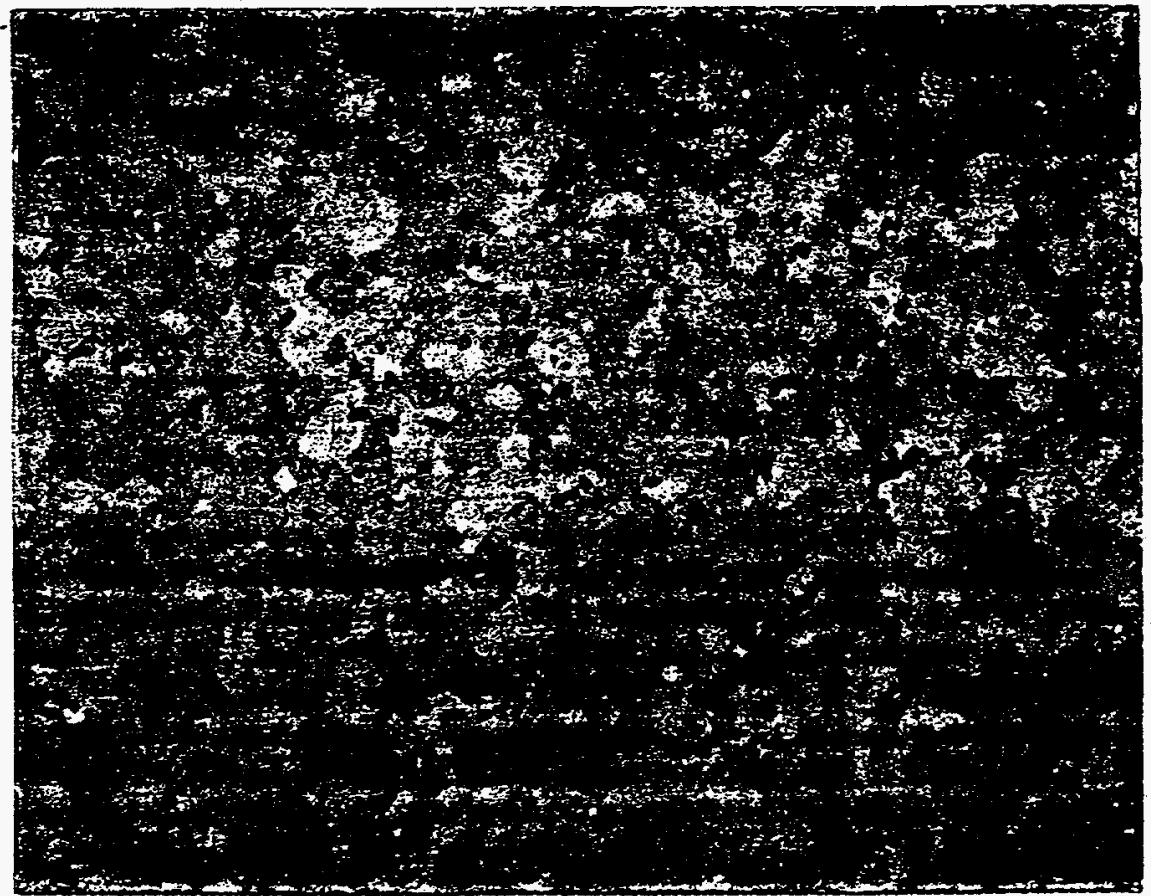

Figure 8 , Microstructure of 3 mole $\% \mathrm{Nb}_{2} \mathrm{O}_{5}$ doped titanium dioxide sintered at $1200^{\circ} \mathrm{C}$ for 3 hours.

It is thought that these voids are formed in the early stages of sintering as the $\mathrm{Ta}_{2} \mathrm{O}_{5}$ or $\mathrm{Nb}_{2} \mathrm{O}_{5}$ dopant begin to react with the titanium dioxide to form a solid solution. As the doping metal cations are integrated into the titanium dioxide rutile crystal structure, the excess oxygen is released. If not allowed to migrate out of the porous ceramic, this oxygen can be trapped at the grain boundaries inside the ceramic. To allow for the oxygen migration, a rest at the temperature where the porosity first was observed was included in the sintering schedule. A series of experiments resulted in developing a sintering schedule with a 1 hour hold at $1050^{\circ} \mathrm{C}$ and then a second hold for 2 hours at $1150^{\circ} \mathrm{C}$. The final density for this doped ceramic was $>99 \%$ of theoretical. Figure 9 shows a micrograph of this highly dense ceramic with minimal voids. 


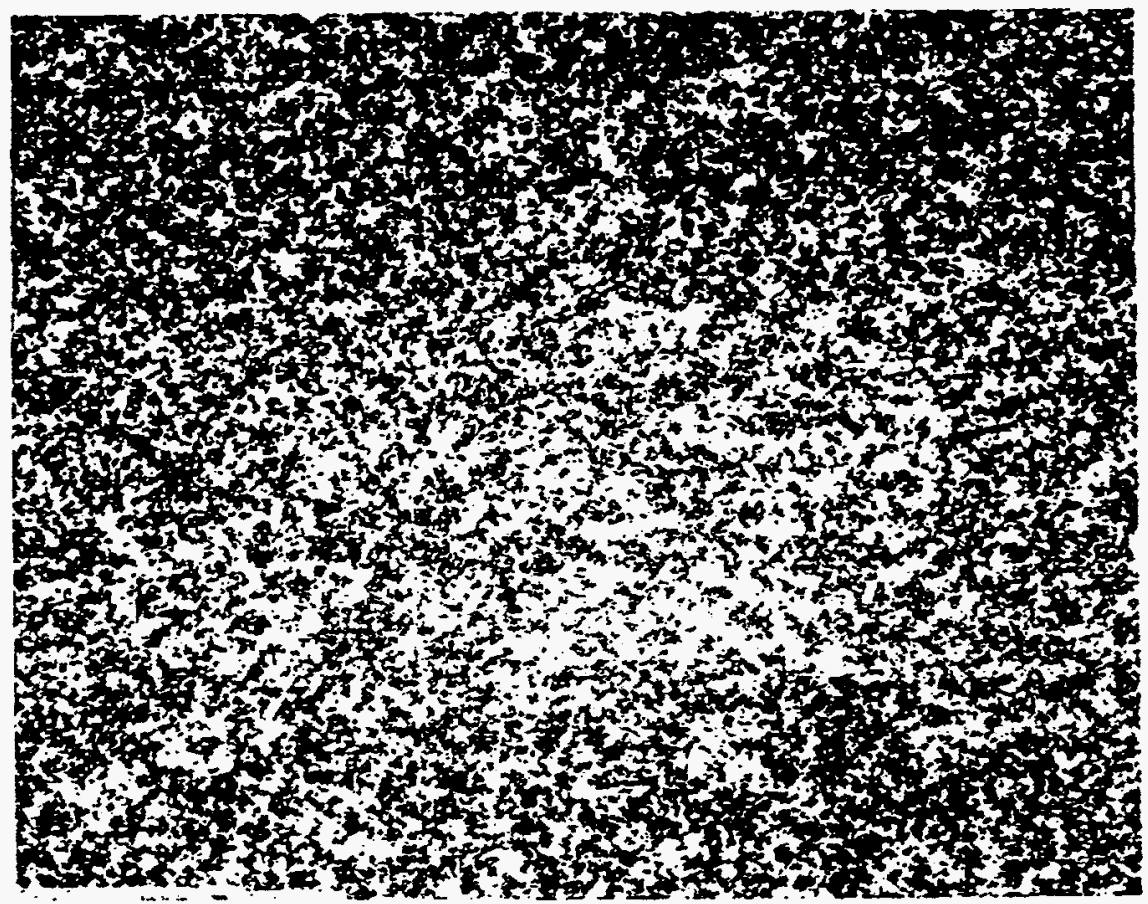

Figure 9, Microstructure of 3 mole $\% \mathrm{Nb}_{2} \mathrm{O}_{5}$ doped titanium dioxide sintered using optimize schedule.

\section{Ceramic Physical Characterization}

Greenware disks were prepared by slip casting of a 95:5 mole ratio $\mathrm{TiO}_{2}: \mathrm{Ta}_{2} \mathrm{O}_{5}$ for use in making flexural test bars. The disks were sintered for two hours at $1480^{\circ} \mathrm{C}$. The disks were then sent out for machining into flexural strength test specimens ( $4.0 \mathrm{~mm} \times 3.0 \mathrm{~mm} \times 45 \mathrm{~mm}$ ) suitable for "configuration B" as outlined in ASTM C 1161-90, "Standard Test Method for Flexural Strength of Advanced Ceramics at Ambient Temperature." Specimens were tested in the "four-point-1/4 point" configuration at room temperature and $800^{\circ} \mathrm{C}$.

Young's modulus, bulk modulus, shear modulus, and Poisson's ratio were measured at ambient conditions with a sonic technique on each of the flexural strength specimens before breaking. The results of this testing and the flexural testing are in Table III.

The room temperature strength compares well with the literature ${ }^{2}$ where average fourpoint bend was reported to be $\sim 18 \mathrm{Ksi}$ for 1 mole \% Ta doped ceramics. The fact that we are above with reported strength value for similar materials is a good indication of the high quality of our ceramics. 
Table III. Physical Property/Characteristic Values for Moduli and Flexural Strength of Sintered 95/5 Mole \% Titania/Tantalum Pentoxide

Greenware Prepared by Slip Casting.

PROPERTY/CHARACTERISTIC

$\operatorname{DENSITY}(\mathrm{gm} / \mathrm{cc}) \quad 4.58$

\% DENSE $\quad 96$

YOUNG'S MODULUS (psi x 10-6) 36

BULK MODULUS (psi x 10-6) 25

SHEAR MODULUS (psi x 10-6) 14

FLEXURAL STRENGTH (Ksi) @

Temperature $\left({ }^{\circ} \mathrm{C}\right)$

23

26.0

800

20.0

One important trend to be noted from this table is the decrease in strength as a function of temperature. This is significant due to the fact that the ambient temperature of the molten salt bath used in magnesium electrolysis is $720^{\circ} \mathrm{C}$. Thus, the operating strength of the ceramic is significantly lower the room temperature strength.

\section{Anode Assembly Development}

The goal for assembly of a successful anode was to completely fill of a ceramic shell with a highly conductive material without cracking the shell during the process. For success, a core formulation must achieve a balance between the following :

1. Achieving good electrical and physical contact with the shell's inner surface.

2. Having sufficient electrical conductivity such that the assembled anode has electrical efficiently equal to or better than graphite anodes.

3. Having thermal expansion characteristics throughout the filling and subsequent thermal cycles such that neither the bond between the core and shell nor the ceramic shell itself will break.

In pursuit of fulfilling the above criteria, a variety of core materials and shell modifications were investigated. 


\section{Core Material Identification}

In order to meet the criteria for a solid core material, a ceramic - metal composite was pursued. The core material must be a strong electrical conductor while having a good thermal expansion match with the ceramic shell. Efforts to develop a suitable metal-ceramic core system for filling the ceramic shells are currently focused on the binary titanium (Ti) copper $(\mathrm{Cu})$ system for the metal component of the core material. Initially, additions of 2-9 weight \% $\mathrm{Ti}$ were made to the $\mathrm{Cu}$. Then silicon carbide (SiC) powders were combined with these alloys to reduce the thermal expansion of the alloy. Unfortunately, the titanium was found to react with the $\mathrm{SiC}$. Titanium carbide was then obtained for use as the ceramic powder. The alloy composition was also shifted to the high titanium side (above $\mathrm{Ti}_{2} \mathrm{Cu}$ ). The liquids in this compositional area strongly wet both the ceramic and graphite.

A composite composition with 50 volume $\% \mathrm{TiC}$ was prepared as a bar at $1100^{\circ} \mathrm{C}$ for thermal expansion measurement and comparison to the 5 mole $\%$ tantalum pentoxide doped, titanium dioxide ceramic shell material. Figure 10 shows the thermal expansion data for these anode components. The graph shows the linear thermal expansion coefficients versus temperature plots for a $62 / 38$ weight $\% \mathrm{Ti} / \mathrm{Cu}$ alloy, the ceramic, and the composite. The liquidus temperature for this alloy is below $1100^{\circ}$. It was thought that the match between the ceramic and the composite were not as close as probably needed. Higher volume fraction ceramic composites were then attempted.

A first attempt was made at filling a shell with the 50 volume $\% \mathrm{TiC}$ composite. The blended mix of $\mathrm{Ti}, \mathrm{Cu}$, and $\mathrm{TiC}$ powders was cold isostatically pressed as short cylinders. These were then hand abraded and inserted into a sintered shell. These filled the shell to within about an inch of its top and most of the diametrical space. For firing it was set vertically into a graphite support cylinder. This was placed into a vertical tube (fused quartz tube) furnace. $\mathrm{A} 3 / 4$ inch diameter graphite rod was set into the unfilled top of the shell. A cylinder of graphite $(3 \mathrm{lb})$ slightly smaller in diameter than the furnace tube, with a center hole fitting over the rod, kept the rod aligned and applied a small load to the core. This assisted in consolidation of the composite core and pushing it against the wall of the shell. The graphite rod was pushed about one inch further down into the shell. Unfortunately, during this "filling" process, the rod was not kept aligned with the anode cracking the anode shell. 


\section{Thermal Expansion Coefficients vs Temperature}

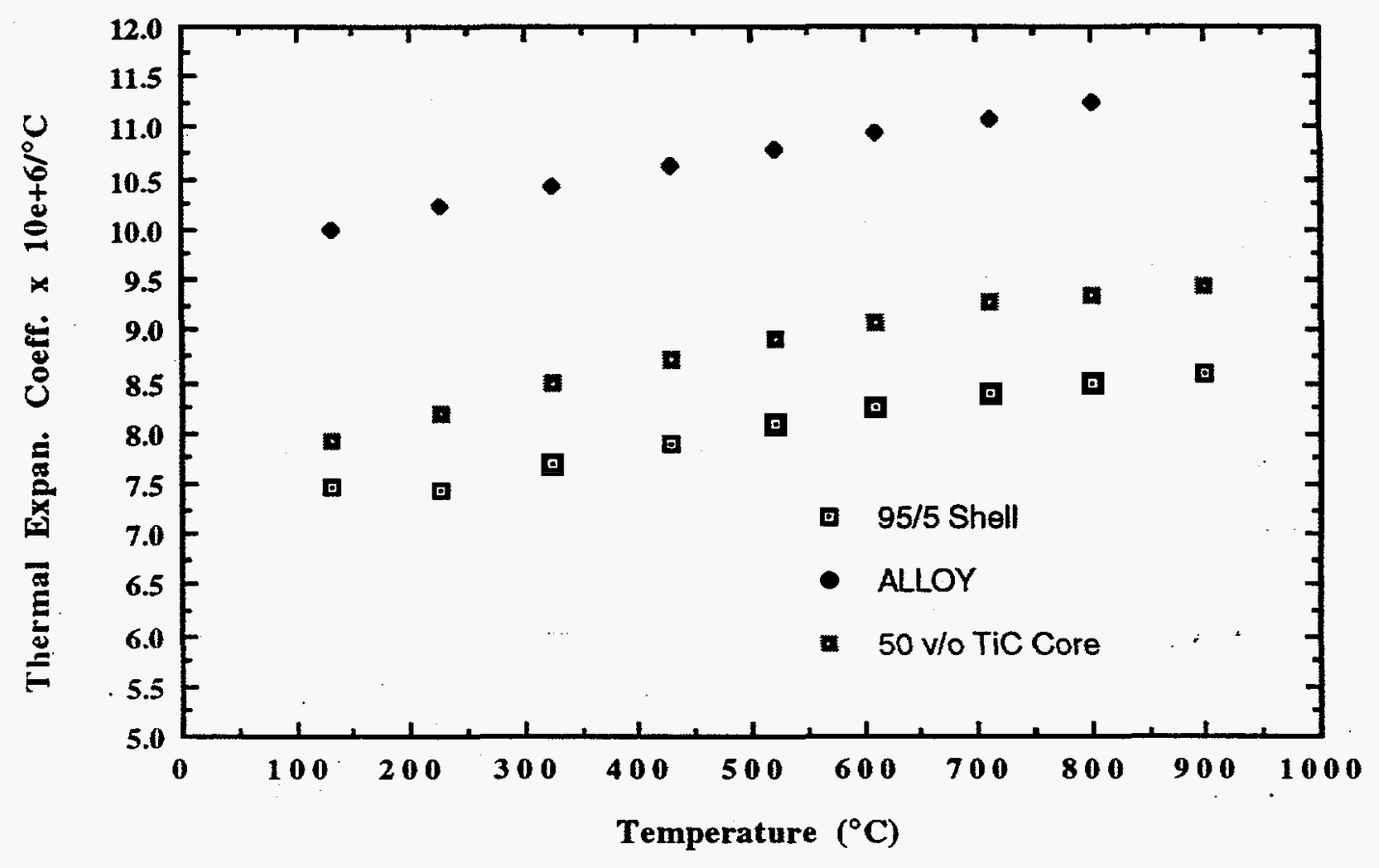

Figure 10, The thermal expansion data for the anode components

\section{Thermal Expansion Characterization}

Cracking of the ceramic shell proved to be a more refractory problem than expected from earlier modeling studies of the expected stresses in the anode. This led to a re-examination of the thermal expansion coefficient of our ceramic material. Previously, the ceramic tested was material that had only gone through the normal sintering cycle. New measurements were done on ceramic that was sintered and then run through the anode core filling process heating cycle. The results of this testing are shown in Figure 11 along with results for the ceramic after only the sintering. The filling cycle results in significantly lower thermal expansion. Figure 12 compares plots of sintered and heat treated ceramic with a composite core that we have used. These results indicate the thermal expansion mismatch and resultant stress must be much greater than previously recognized.

Knowing that the thermal expansion mismatch between the ceramic shell and composite is too great, new lower thermal expansion composites must be developed. Through differential scanning calorimetry, it was found that the alloy made from pure metals was not at phase equilibrium in the composite. Therefore, pre-alloyed material was obtained to ensure that the correct phases were being created. Higher ceramic component 
formulations were also studied. A change in the alloy composition to allow incorporation of a lower expansion ceramic component was also considered.

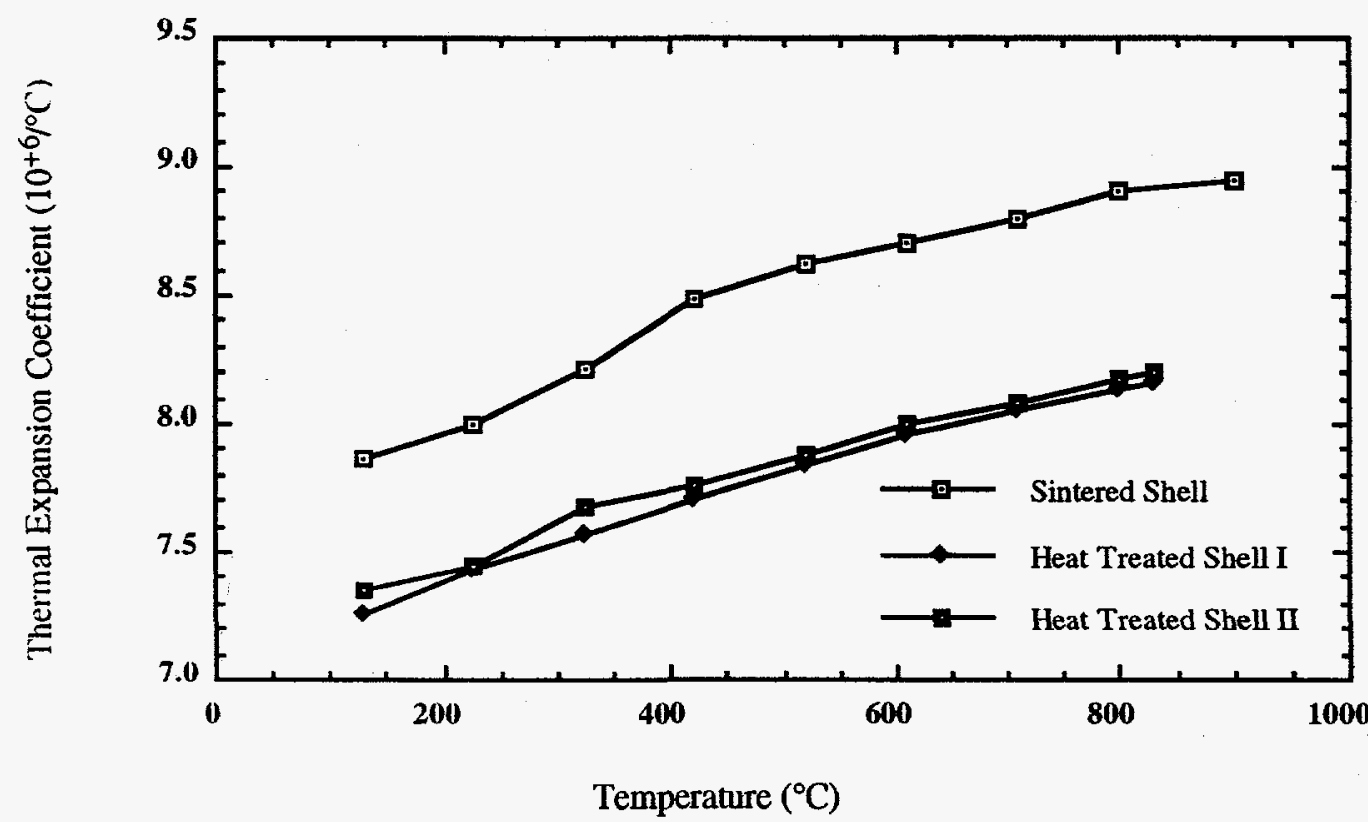

Figure 11, Effect of the thermal cycle in filling an anode on the thermal expansion coefficient of the ceramic.

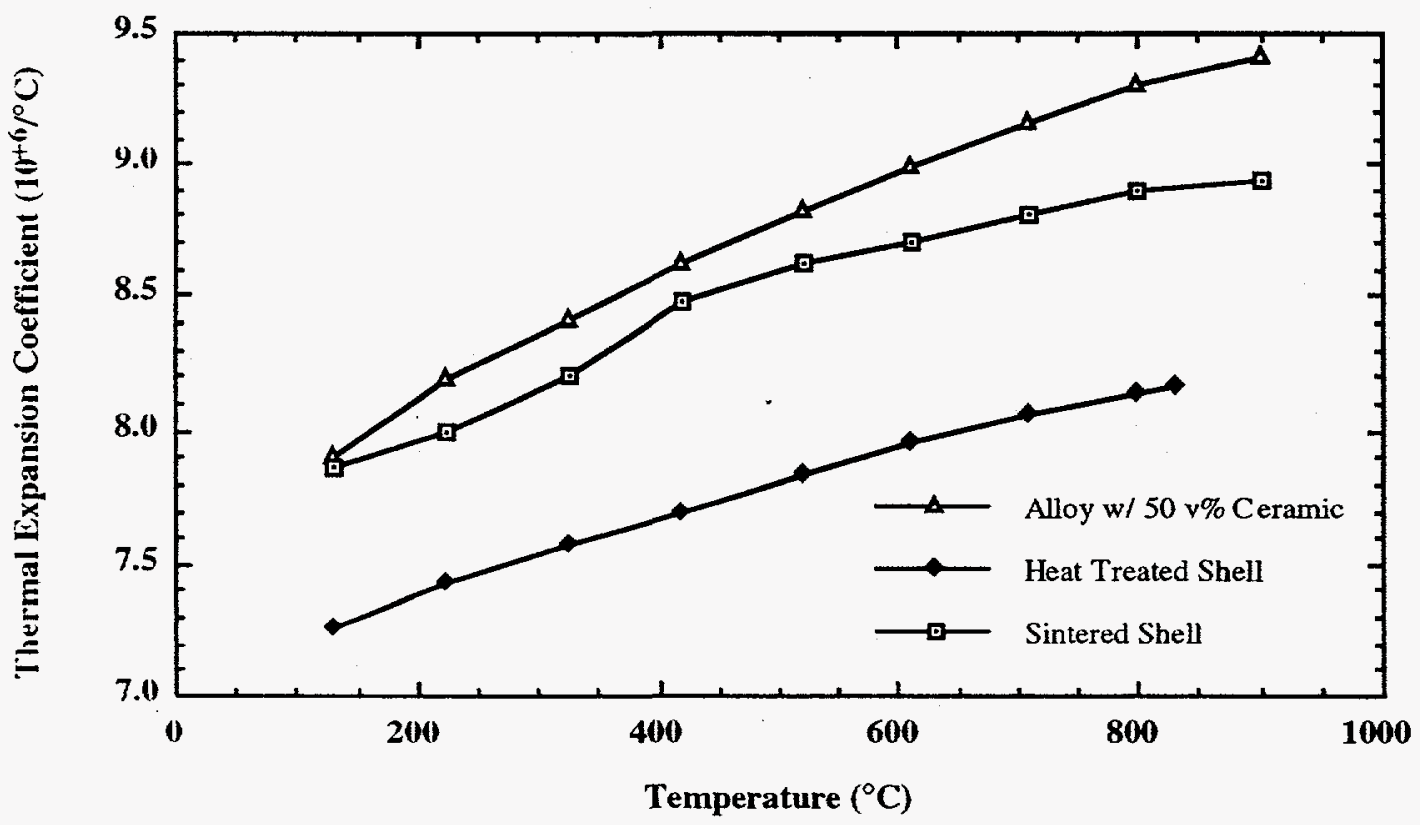

Figure 12, Comparison of thermal expansion coefficients of sintered and thermally cycled ceramic to core composite.

Finite Element Analysis Stress Modeling 
The proposed structure of the ceramic anode requires proper matching of the coefficients of thermal expansion of the composite core material and the inert ceramic shell. A coupled dynamic heat transfer - thermal stress analysis modeling study was being used to provide design information on geometry and material composition for laboratory scale ceramic anodes. For performing the modeling calculations, the commercially available computer program, trade named ABAQUS, was used. ABAQUS is a robust finite element program capable of making dynamic heat transfer and thermal stress calculations for complex geometries. The program inputs are geometry, moduli, coefficients of thermal expansion, temperature dependent thermal conductivities and specific heats, and the thermal and physical boundary conditions. The plan called for making an initial set of calculations early in the research program using material properties found in our literature search for the proposed core composite components copper and silicon carbide.

The ceramic anode modeled is comprised of a titania shell with a current carrying Titanium carbide (TiC) ceramic/copper (Cu) metal composite core. Thermal stress modeling results on the lab scale anode, shown in Figure 6 for a specific titania shell thickness, reveals that the optimal core composition that results in the lowest thermal stresses is approximately a $50 / 50$ volume ratio $\mathrm{TiC} / \mathrm{Cu}$ composite composition.

The results also show that at higher percentages of $\mathrm{SiC}$ in the core composite, the thermal expansion mismatch and the increased modulus, or stiffness, of the core material results in increased tensile stress levels concentrated at the core-shell interface. Core materials with $\mathrm{TiC}$ component percentages less than $50 \%$ also experience increased tensile stresses but these are concentrated in the shell's rounded bottom area due to thermal expansion mismatch. These results point to pursuing the $50 / 50 \mathrm{TiC} / \mathrm{Cu}$ core composite to minimize thermal tensile stresses.

Simulations have also been performed on the potentially more severe, transient stress evolution that occurs in actual operation of the magnesium cell as the anode is initially placed into the reactor. Results from this simulation have shown that the optimized $50 / 50 \mathrm{TiC} / \mathrm{Cu}$ composite core anode design should survive the predicted transient thermal stress levels. Thus the results of these calculations on the lab scale anodes indicate that they should have little problem surviving the thermal stresses during any phase of operation testing. 


\section{Anode Fabrication}

More recent efforts to fill the ceramic shell with the composite core were done with a support, load application apparatus. The apparatus or filling stand is shown in Figure 13. This stand eliminates the alignment problem and also increases the filling load that can be applied. The stand is made from stainless steel. The force of the weights is applied to the core by the graphite ram. Complete filling of the shell by the core has proven difficult.

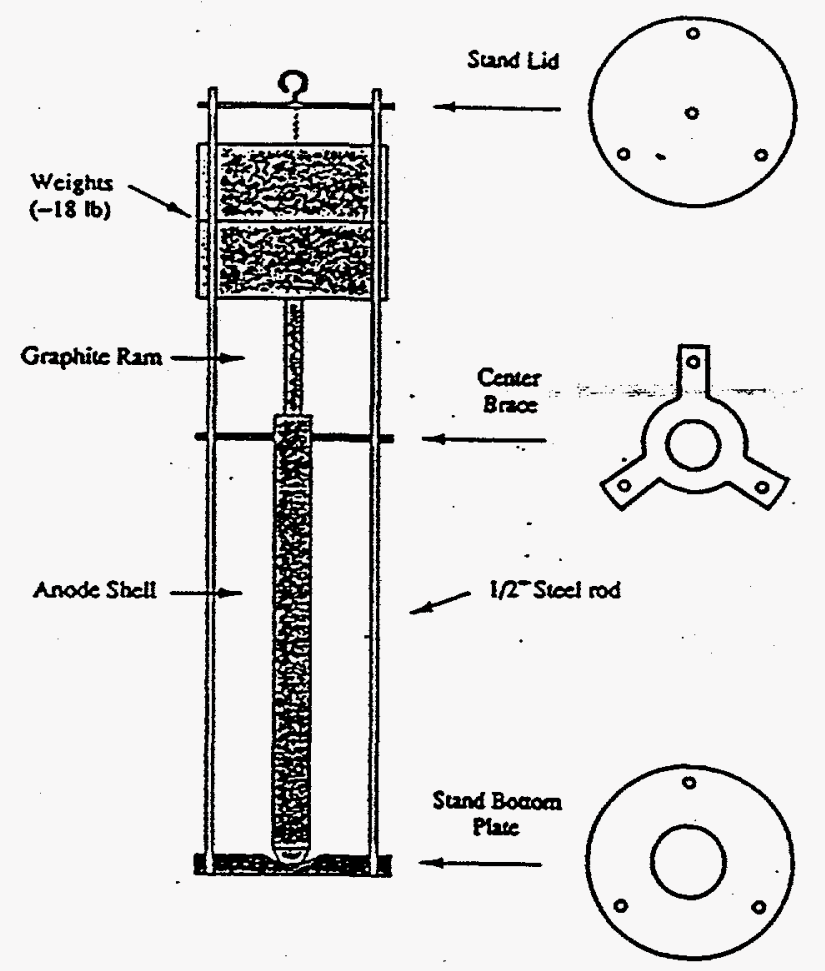

Figure 13, Furnace stand for filling laboratory scale anodes.

Based on computer modeling of this anode, it was evident that the magnitude of the hoop stress in the anode when cooled to room temperature would be near the critical stress. Physically, any cracking would be attributed to the thermal contraction of the graphite being less than the shell-core system. Experimental results show the tensile hoop stress exceeds the strength of the material surrounding the graphite rod in most cases. This results in the formation of cracks in the composite and shell along the length of the anode. In 6 of the 8 runs cracks originating out from the graphite-core interface and propagating through the ceramic shells were formed.

Stainless steel rods, also a half inch in diameter and varied in length from 9.5 to 10.5 inches, were next tried as the ram. These have thermal contraction greater than the core and shell. The steel's higher thermal contraction should load the core and shell into compressive stress after the alloy of the core solidifies and will no longer plastically 
deform. Though not yet confirmed through modeling, it appears the shear strength of the ceramic shell is exceeded. Cracking of the ceramic shell occurred in 5 experiments with stainless steel as the ram. The composite core successfully withstands the stress on it. The results suggest the bond between the shell and core is strong enough to transfer sufficient stress to the shell to cause the shell to fracture.

One of these stainless steel rod runs came very close to completely filling the cavity of the shell. Most of the ceramic had to be removed with a hammer. Filling is estimated to have been about 99 volume \%. The stainless steel rod and core are shown in Figure 8.

Because of cracking, the solid stainless steel rods were abandoned for hollow half inch outside diameter stainless steel tubes. With this change it was hoped the stainless steel would yield rather than cracking the ceramic in cooling. However, the tubes were not sufficiently rigid at the necessary temperature and they bowed or buckled and either did not go in centered or did not go in far enough.

Finally, cast gray iron half inch diameter rods were tried because cast iron has thermal expansion cluser to the shell and core than any of the previously tried materials. Unfortunately, cast iron softens too much at the filling temperature and resulted in the same types of failure as the hollow stainless steel tubes.

\section{Pre-densified SHS Core Material}

The core material is a combination of metal components (alloy) and a ceramic component. The former are used for their electrical/thermal conductivities and the latter is used for its thermal expansion reduction. Prior work had been with metal powders (not alloyed) and a ceramic powder blended together to achieve an alloy-ceramic composite. The blended powders were cold pressed and shaped to fit inside the ceramic shell. The loaded shell was set, with a push rod in the top, in the furnace stand 5 . The furnace stand holds the shell and push rod in alignment vertically while a load is applied during the thermal cycle. As the metals alloy and melt, the load pushes the composite (consistency believed to be like wet sand) down into the shell. When the composite has been rich enough in liquid to flow sufficiently to fill the cavity, the thermal expansion has been too high and the shell has cracked in cooling. Reducing the alloy (or liquid) content results in an incompletely filled shell.

A new approach to the core material is preparation of predensified granules of a composite composition. A unique processing method using self-propagating hightemperature synthesis (SHS) to prepare these densified granules has been developed. This method has overcome phase segregation problems encountered using conventional 
methods. The SHS process involves the exothermic self-sustaining reaction of a powder charge into a homogeneous powder compact or a dense ceramic body. The powder charge is packed into a crucible where a resistively heated tungsten filament ignites an exothermic reaction converting, in this case, the titanium, carbon, and copper powder mixture into homogeneous, titanium carbide reinforced titanium/copper alloy cermet. Figure 14 presents a schematic of this process. The resultant product is a porous cake. This porous cake is then crushed into 1-3 mm granules. Using these granules as a fill material with our conventional core filling procedures results in a uniform filling of the shell with a uniformly porous core. Figure 15 is a sketch showing the anode design using the SHS predensified core material. Radiographs (gamma ray exposure) of filled anodes indicate achievement of good contact, i.e. filling, at the core-shell interface. To improve the electrical properties of the anode using the SHS core material, minor additions $(-10 \mathrm{wt} . \%)$ of titanium/copper alloy powder are mixed with the SHS granules before being used in the filling process. Anodes fabricated with this method have improved electrical properties, as shown by resistivity measurements on filled anodes.

Dilatometer studies of linear thermal expansion, see Figure 16, show a reasonable match of these new core materials with the ceramic after it has had the thermal treatment of the filling cycle (the filled circles). The porosity of the SHS material has the added affect of reducing the modulus of the core. By reducing the modulus (or stiffness) of the core material, any stresses generated by the thermal expansion mismatch between the core and the shell are partially alleviated by the core's ability to deform and not transmit the stresses to the fragile ceramic shell. 


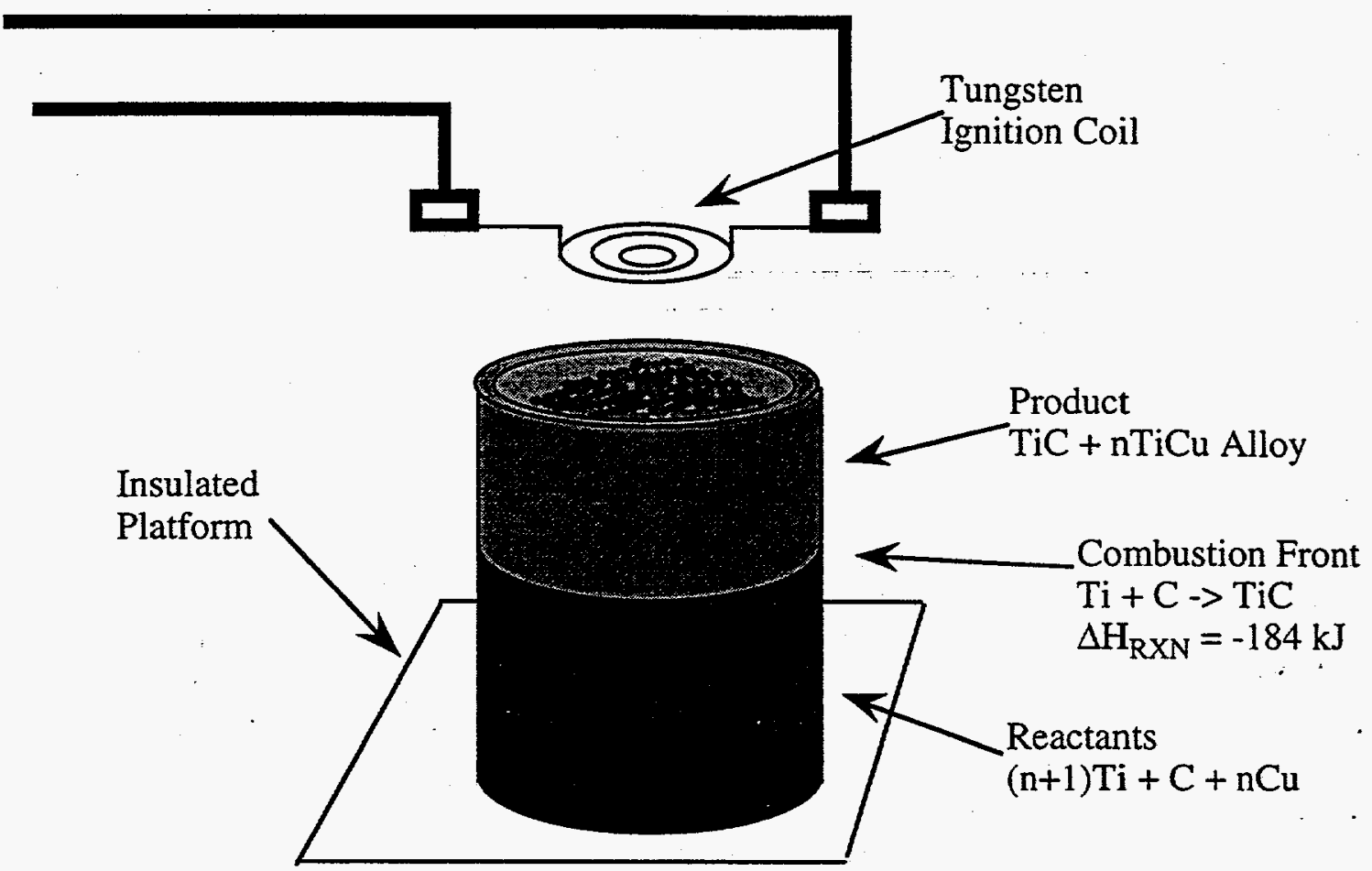

Figure 14. Schematic view of an SHS reaction 


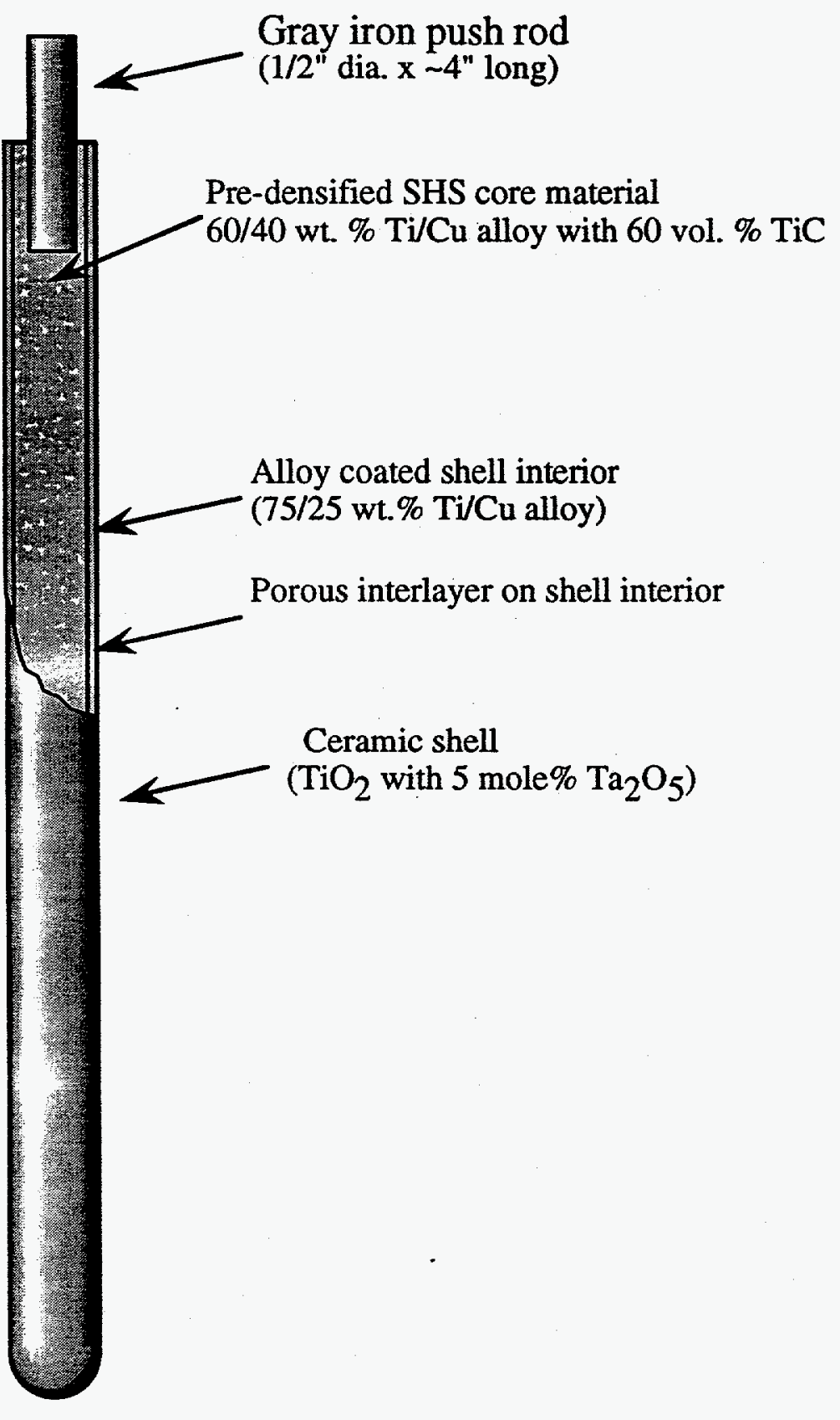

Figure 15. Sketch of a lab scale anode using the SHS core material 


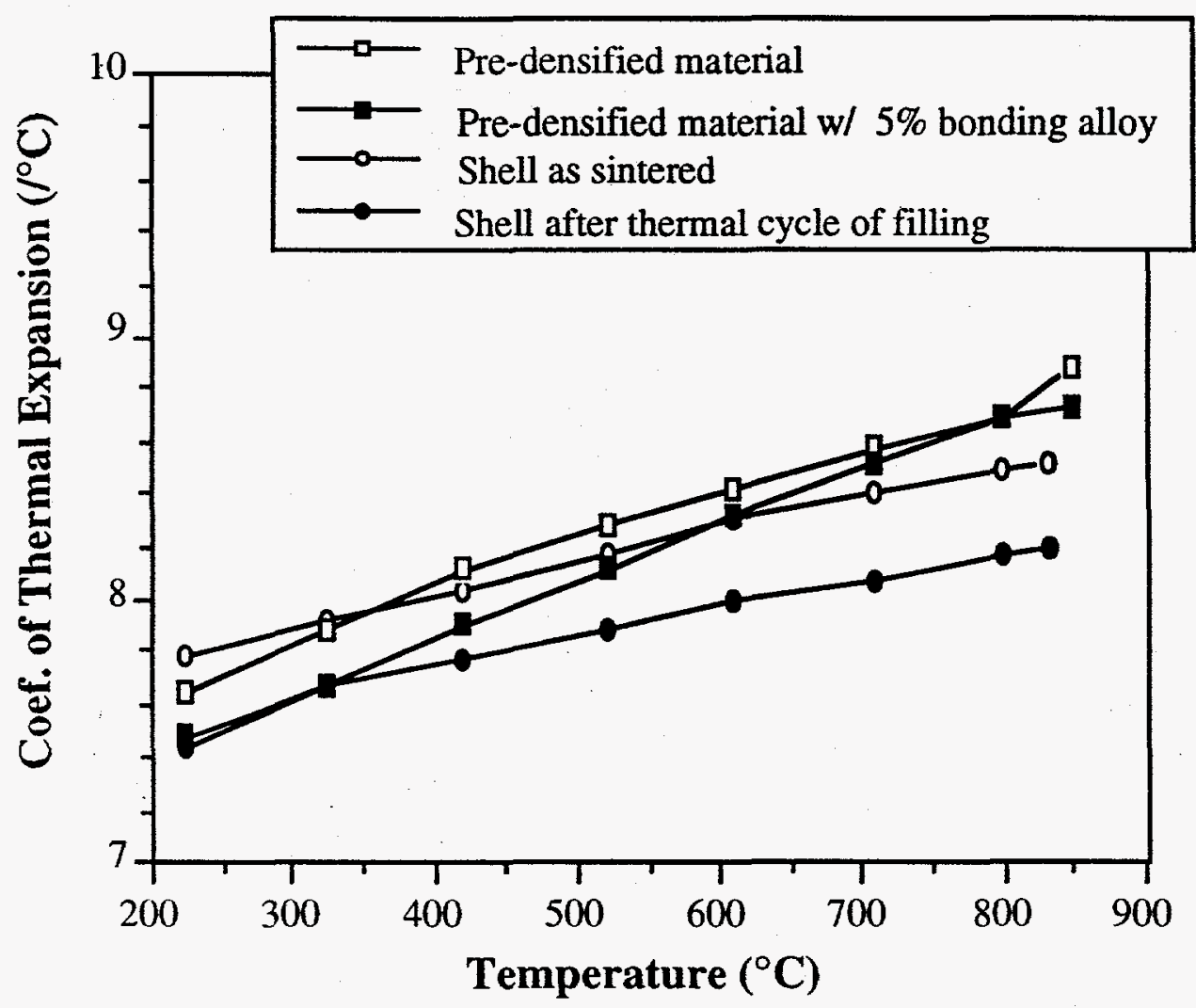

Figure 16, Thermal expansion coefficients of shell and core materials.

\section{Bonding of Shell and Core}

The inner surface of a typical sintered ceramic anode shell is very dense and smooth, like a mirror. This has made the chore of developing a physical or interlock bonding between the core and shell. The bond is important for both good electrical conduction and physical strength. After failing in attempts to develop a chemically modified interlayer, work has been directed at roughening the inner surface with the hope of producing some degree of interlocking structure at the interface. Chemical etching, other than with strong hydrofluoric acid, proved unsatisfactory. Use of hydrofluoric acid was noi continued because of satety concerns.

Success has been achieved in making a surface providing porosity for the liquid portion of the core to penetrate and interlock. Figure 17 shows photomicrographs of anode shell inner surface cross-sections. The upper photo (as fractured cross-section) is of the normal dense surface and the lower photo (fractured and polished cross-section) is of the porous rough surface. Work is in progress to minimize the thickness of the porous interlayer and to test with the core system to determine the penetration into and bonding to the interlayer. 

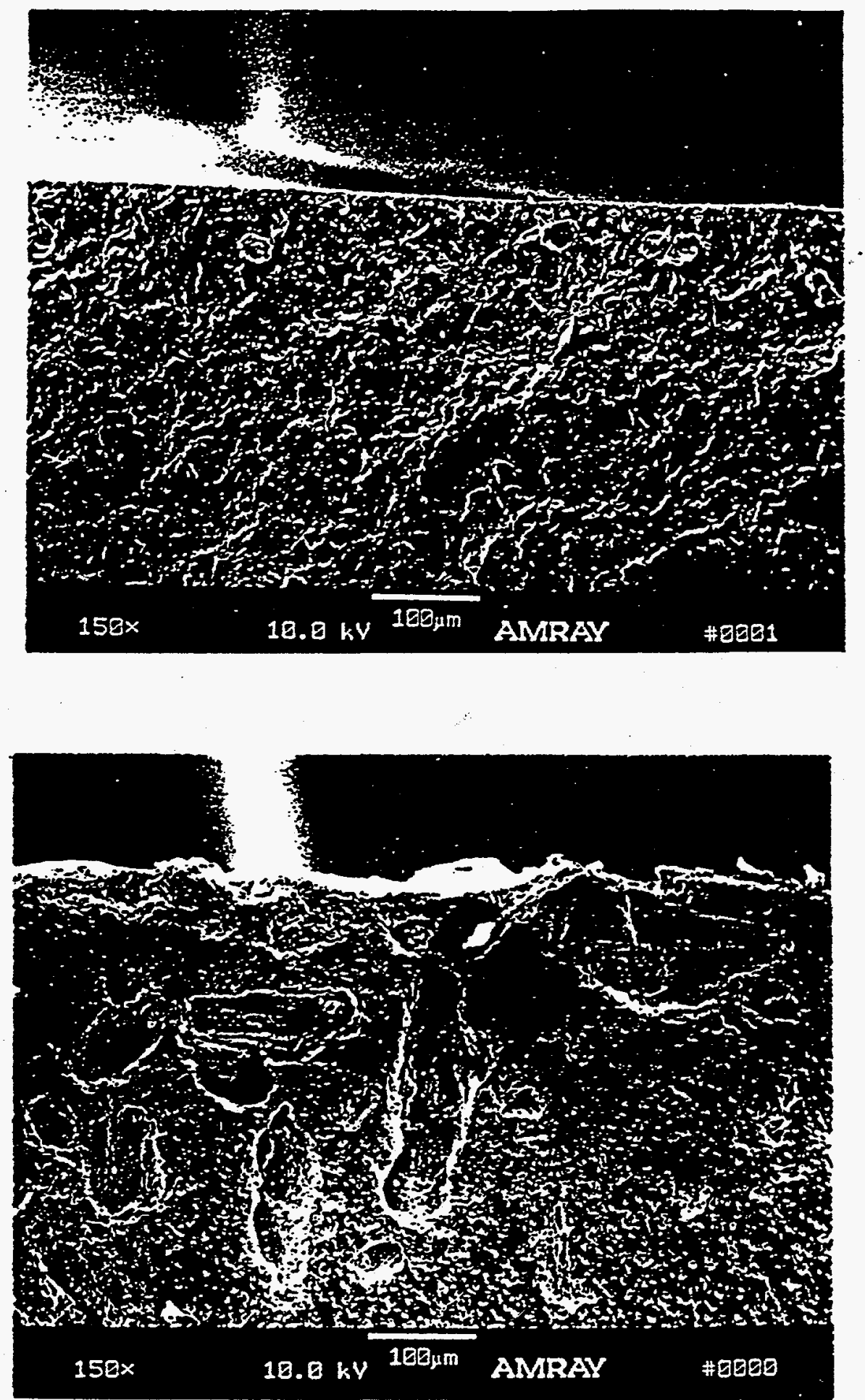

Figure 17. Photomicrographs of cross-sections of sintered anode shells with and without porosity to enhance core/shell bonding. 


\section{Alloy Precoating}

In filling the anode shell with predensified granules, contact between the shell and core material is limited by the porous structure. To improve electrical performance, a coating of alloy is applied to the inner surface of the ceramic and thermally treated to bond. This is referred to as "Shell's precoated porous interior surface" in Figure 15.

\section{Electrical Performance Optimization}

The reduced modulus and the improved filling characteristics of the pre-densified core material permits a wide range of material and design variations to be investigated without jeopardizing the physical integrity of the anode. The benefits from this unexpected design flexibility were explored through anode design iterations.

The high porosity $(\sim 50 \%)$ of this core material has the benefit of a lower elastic modulus. The elastic modulus, or material stiffness, reduces the stress carrying ability of the composite core. Thus, a larger thermal expansion mismatch between the core and the shell can be tolerated without cracking the shell. This opens the door to a wide range of design and material development. The porosity of the system will also allow the anode to meet the weight requirements for full scale operational testing.

The significantly reduced shrinkage of the pre-densified composite core material eliminates the need for a relatively low viscosity melt to allow complete filling. This reduced shrinkage allows internal anode design modifications to be possible. One such internal design modification is to add a current carrying rod down the center of the core composite running the length of the anode. The motivation for having an imbedded conducting rod is to reduce the electrical path length through the high porous and thus reduced conductivity core composite. In an anode with a highly conducting rod imbedded in the core, the electrical path length is reduced from several inches to approximately $3 / 8$ inch. Copper, titanium, and mild steel rods were investigated for this use. The resistivity testing of two anodes with a copper rod imbedded in the core composite showed a dramatic, $\sim 10$ times, reduction in the high temperature resistivity of the anode. However, when one of these anode was sectioned for post-mortem analysis, it was revealed that the copper rod had been completely absorbed into the composite core material during the filling process leaving behind a hole where the rod was initially positioned. The titanium rod showed a similar decrease in anode high temperature resistivity. The titanium rod remained intact after the filling process. Using the mild steel rod produced the most promising results by yielding a high temperature resistivity which is lower than the tested graphite 
anode high temperature resistivity. The combination of the core composite attributes of reduced shrinkage, modulus, and strength is the key to allowing these types of anode design modifications.

\section{Electrical Testing}

In order to perform a pre-evaluation of the electrical performance of the developmental anodes and also as a quality control check on the filled anode integrity, a high temperature resistivity measuring device was designed and constructed. A high temperature device is needed due to the varied temperature dependence of electrical resistivity for different materials. With respect to the anode, the resistivity of the metallic core would be expected to decrease with temperature while the resistivity of the ceramic shell would increase. Thus, a high temperature measuring device was needed to gain . accurate resistivity data. A schematic of the high temperature testing apparatus is shown in Figure 18 . The high temperature resistivity measuring device uses a four point resistivity measurement scheme. The temperature control and data collection is performed by a Camile ${ }^{\mathrm{TM}}$ control system. The testing is performed in a controlled atmosphere furnace.

To graphically demonstrate the usefulness of this type of measurement device, Figure 19 presents a resistivity versus temperature graph for a ceramic anode and a graphite anode. This graph shows the dramatic decrease in the resistivity as a function of temperature for the ceramic anode as compared to the graphite anode which is relatively constant. The graph also shows that the electrical resistivity of the ceramic anode is very comparable to graphite at $700^{\circ} \mathrm{C}$. At $700^{\circ} \mathrm{C}$, the ceramic anode had a minimum resistivity of $0.645 \mathrm{~m} \Omega-\mathrm{cm}$ which is lower than the graphite's resistivity of $0.907 \mathrm{~m} \Omega-\mathrm{cm}$. This anode design is shown in figure 20 . 


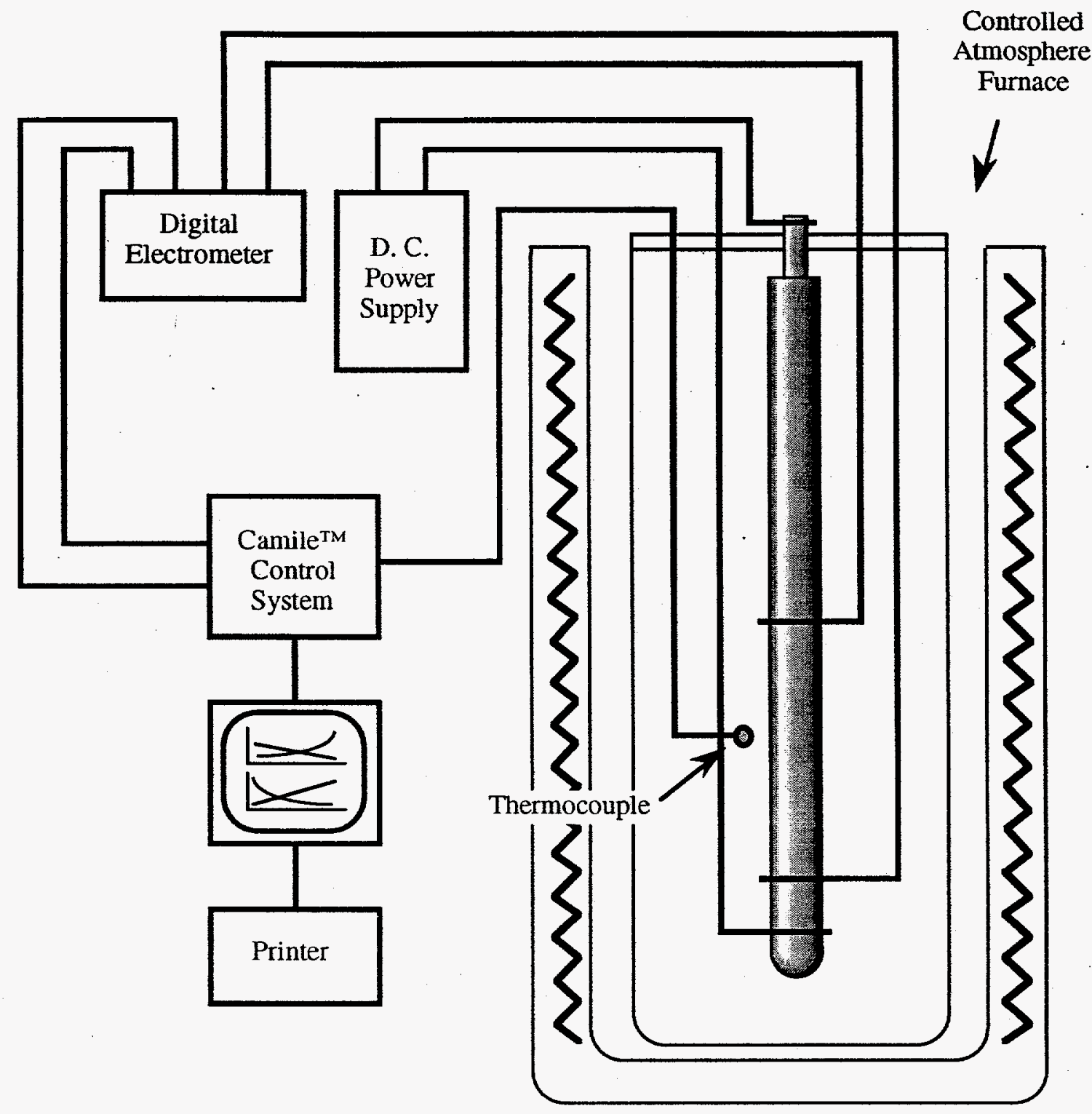

Figure 18 , Sketch of the high temperature resistivity testing apparatus. 


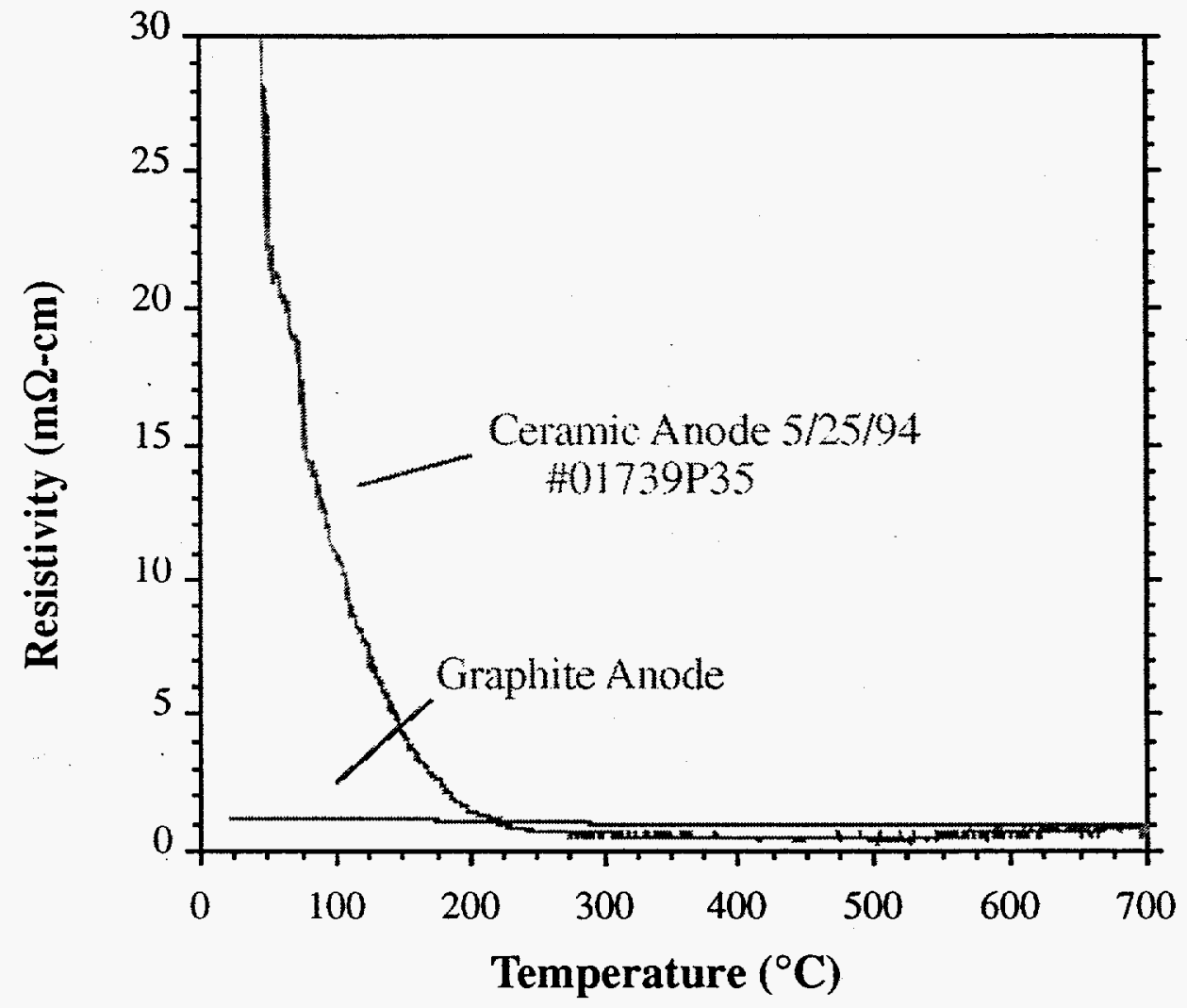

Figure 19, Resistivity versus temperature graph. 


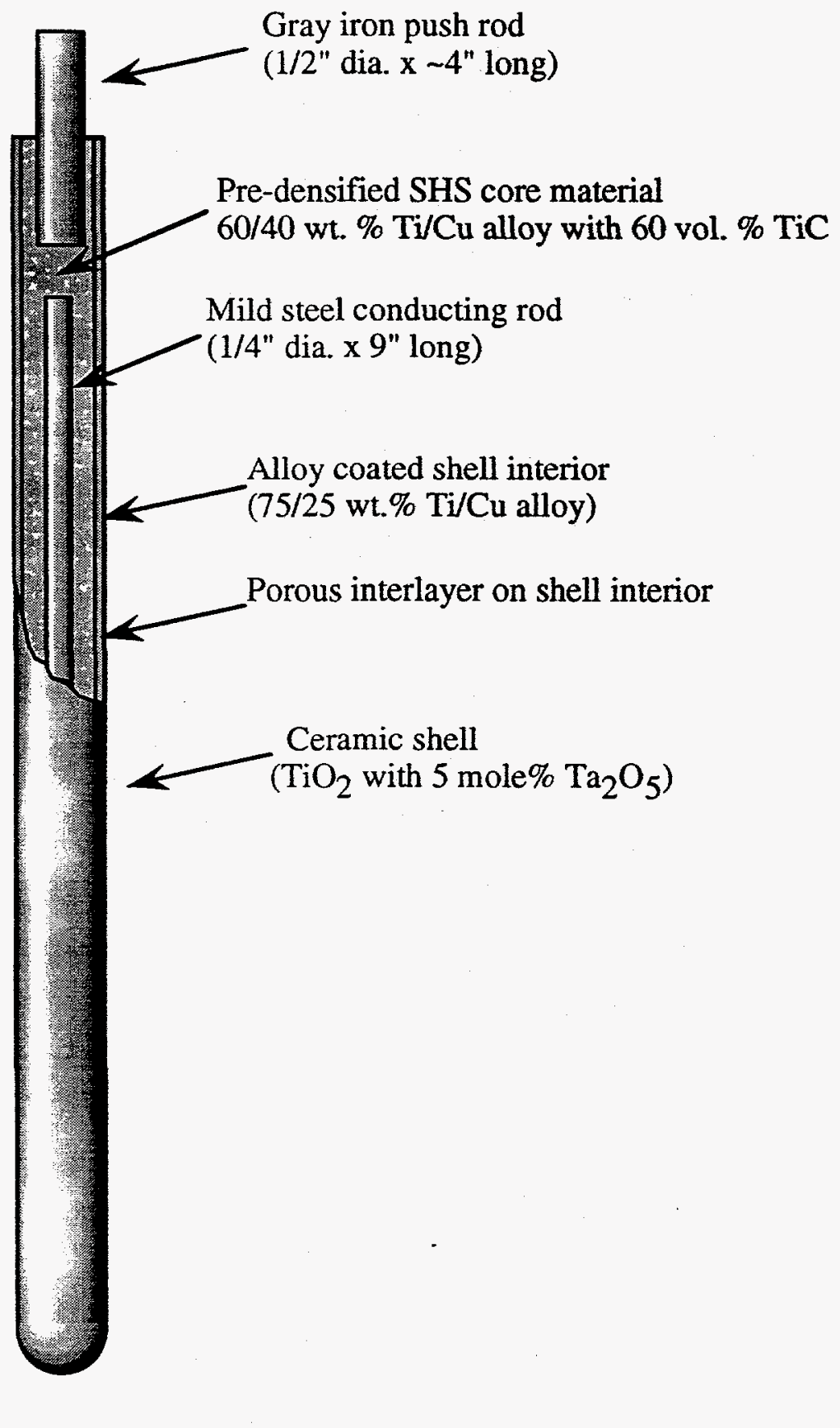

Figure 20, Sketch of lab scale ceramic anode with imbedded conducting rod. 


\section{Raw Material Cost Reduction}

To ensure the eventual implementation of the ceramic anode into the production magnesium electrolysis cell, a preliminary cost analysis was completed. The analysis revealed that the cost of the raw materials was of potential concern. Reducing the expected raw material cost while maintaining the electrical performance of the anode became a important development issue. The following work topics were directed at exploring different methods to reduce the cost of the raw materials to be used in the full scale anode:

1. Examine variations in the composition of the ceramic shell.

2. Investigate substitutions of less costly materials.

3. Introduce and demonstrate design changes to reduce overall material costs.

\section{Ceramic Shell Composition Variations}

The protective ceramic anode shell is a titanium dioxide ceramic doped with small additions of tantalum pentoxide. During the sintering process, this ceramic combination will form a solid solution material. When cooled, the resultant ceramic has high corrosion resistance as well as the unique property of being a semi-conductor (in general, ceramics are electrical insulators). While this ceramic shell is the enabling technology for this project, it also has the main raw material cost. More specifically, approximately $85 \%$ of the raw material cost comes from the 5 mole $\%$ tantalum pentoxide doping of the titanium dioxide ceramic. Thus, reducing the dopant level in the ceramic shell would lead to significant raw material cost reductions.

The titanium dioxide - tantalum pentoxide ceramic material will form a solid solution composite in the doping range of 1 to 5 mole $\%$ of tantalum pentoxide. A study was undertaken to evaluate the potential of reducing this doping amount while maintaining the electrical properties cause by the dopant additions. Dopant levels of 5,3,2, and 1 mole $\%$ were investigated. We were able to sinter all of these compositions into dense ceramic rods. The high temperature electrical properties of these rods were then tested. Figure 21 presents the results of this test series. This graph shows that there is no measurable change in the electrical properties of the ceramic composite when the dopant level is reduced from 5 mole $\%$ to 3 and then 2 mole $\%$ tantalum pentoxide. However, the electrical resistance of the 1 mole \% dopant composite has a higher resistance and thus poorer electrical properties. 
Anode shells of the 3 mole \% tantalum pentoxide doping level ceramic were fabricated and were tested in the laboratory scale magnesium cell to investigate wear characteristics as compared to the higher level doped ceramic.

\section{Material Substitutions}

Material substitution was another raw material cost reduction route being investigated. Niobium pentoxide has been selected as a potential candidate to replace tantalum pentoxide as the ceramic shell dopant. Niobium pentoxide has similar electrical valence properties to tantalum pentoxide. Figure 21 shows a electrical resistivity data point that shows that a niobium doped titania ceramic has equivalent, if not slightly better, electrical properties compared to the tantalum doped system. The raw material cost for the shell could be reduced because niobium pentoxide is $1 / 4$ of the cost per pound than tantalum pentoxide and less weight $(\sim 44 \%)$ would be needed to reach the $3 \%$ molar doping level due to its lighter molecular weight.

\section{Anode Design Variations}

There are several anode design variations that can be implemented to further reduce the raw material cost of the anode. A promising idea is to make a gradient ceramic shell that would have a "standard" titanium oxide - tantalum pentoxide lower portion and a pure titanium dioxide upper portion. Since only the lower portion of the anode shell will be electrically active, only the lower region of the shell needs to have the tantalum pentoxide dopant. Since the tantalum pentoxide is the dominant factor in the raw material cost, this gradient shell design would result in significant cost reductions.

We have explored two methods to make this gradient composition shell design. One method is to cast the ceramic shell in two halves. The lower closed end portion of the anode shell would be comprised of the "standard" titanium oxide - tantalum pentoxide composite. The upper portion would be cast as an open ended tube of pure titanium dioxide. The two halves would then be joined and sintered into a dense ceramic whole. Initial joining studies have shown that this approach is possible but would require further effort to increase the quality of the joint. The second method to achieve the gradient composition shell would be to cast the two halves as one piece by layering the slip as it is poured into the shell mold. Initial attempts at casting a gradient composition, small shell were successful. 
Both of these cost saving measures require significant development work. The work to date has been performed in a exploratory proof of concept framework that can be more fully investigated if the raw material cost issues remains critical.

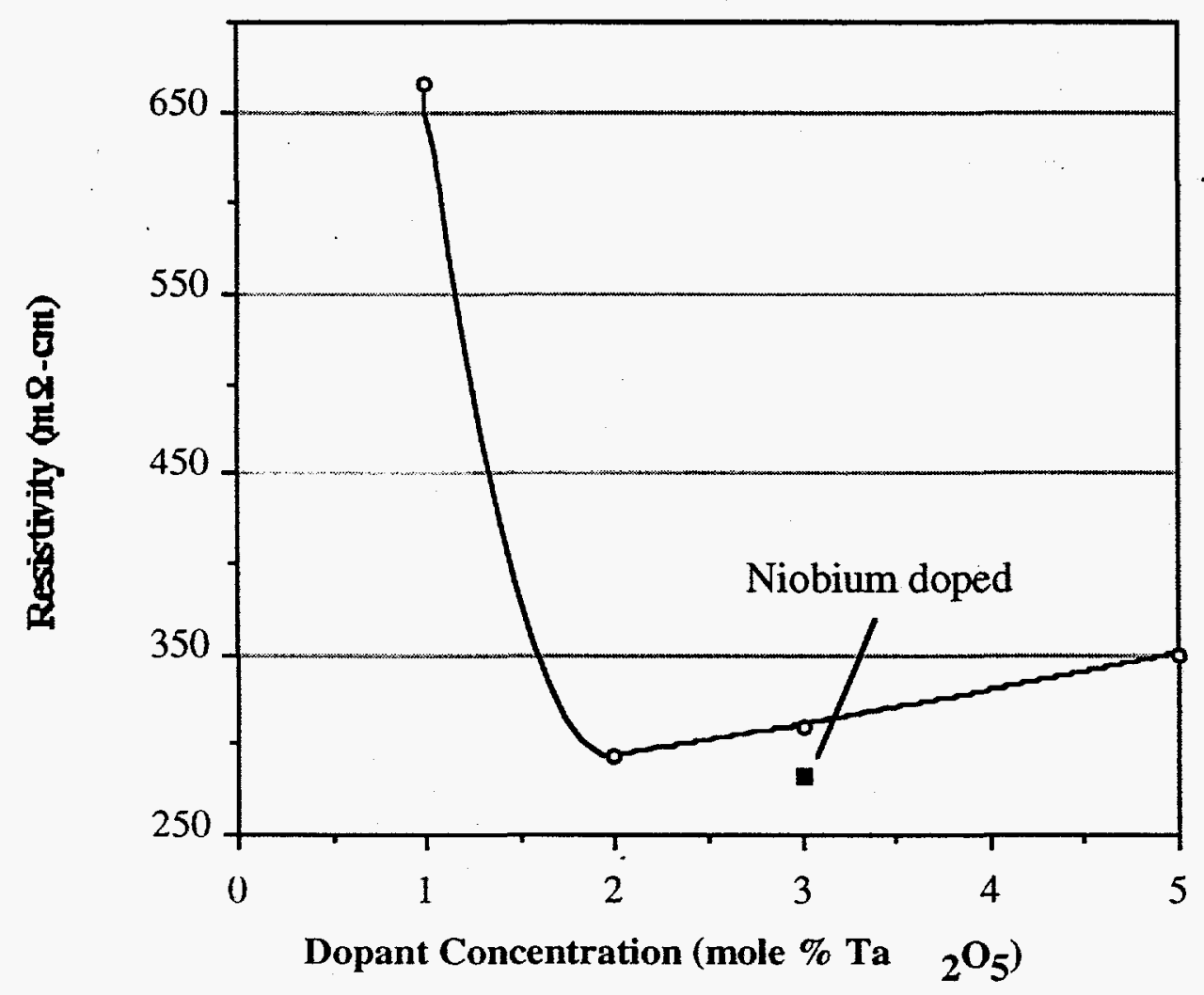

Figure 21, Graph of the electrical resistivity as a function of the tantalum pentoxide ( $\mathrm{Ta} 2 \mathrm{O} 5$ ) doping level of the titanium dioxide ceramic anode shell material. 


\section{Laboratory Scale Magnesium Cell Testing}

Dimensional stability or corrosion resistance and good electrical performance of the ceramic anode are the key material properties. The corrosion resistance is tested in a laboratory scale, magnesium producing electrolytic cell. Figure 22 presents a sketch of this lab scale cell. A cell consists of a 2 liter quartz crucible which is supported on refractory brick in a furnace heated with metallic heating elements. The electrolyte is a molten mixture of chloride salts maintained at a temperature of $700-720^{\circ} \mathrm{C}$. The cathode is a rectangular steel piece connected to the electrical supply by a steel rod. The rod is protected by an alumina sleeve, and clamped in position. The anode is also clamped in position in order to maintain the desired anode-cathode spacing, usually about 1 inch. Hydrous magnesium chloride is fed into the top of the cell to maintain the desired level of magnesium chloride in the electrolyte. The anodically produced chlorine was swept from the cell via a vacuum system. The molten magnesium was removed from the cell daily, and weighed to determine the cell efficiency. The cell was continuously monitored for current, voltage, and temperature. The cell operates using the same salt feed composition and operating temperature ranges used in the production magnesium cell.

Early attempts to fill the ceramic shell with a solid, thermal expansion matched metallic core composite met with limited success. During the filling process, the molten viscosity of the metallic composite core was too large to achieve the complete filling of the ceramic shell. This molten viscosity problem was overcome by using a pre-densified porous composite core material. Granules of the pre-densified porous material were used in the filling operation in place of a iso-pressed powder mixture used in the solid core designs. The nature of the pre-densified material does not require the low viscosity melt needed by the powder compact method to completely and uniformly fill the ceramic shell. This pre-densitied porous material also has several additional advantages in anode design llexibility, weight, and cost.

\section{Initial Magnesium Cell Lifetime Results}

Two lab scale ceramic anodes were tested in the lab scale magnesium cell. Both of the ceramic anodes tested had similar design components as sketched in Figure 20. Both anodes designs had a $\mathrm{Ta}_{2} \mathrm{O}_{5}$ doped $\mathrm{TiO}_{2}$ ceramic shell, alloy coating on shell interior, predensilied porous core 


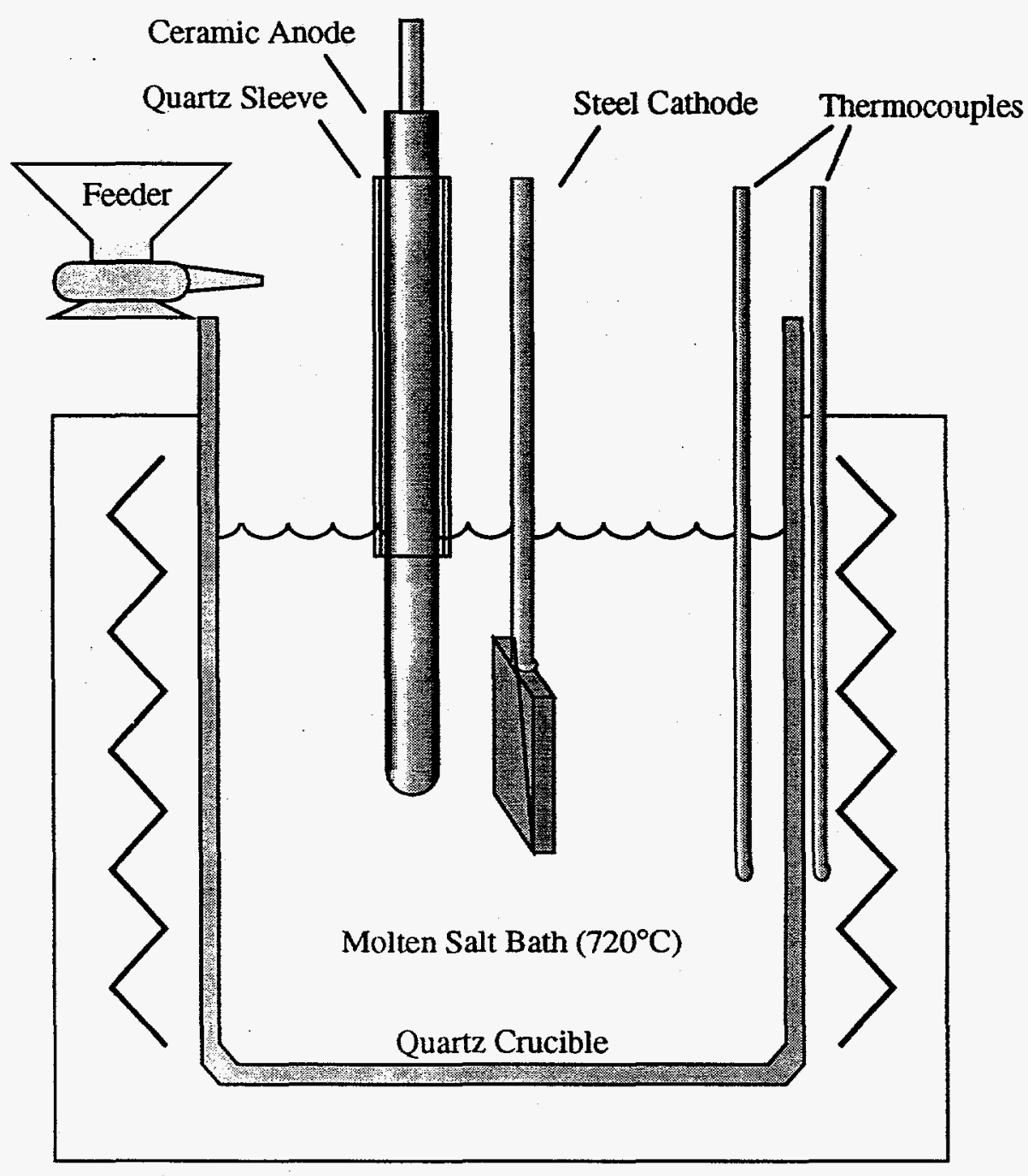

Figure 22, Sketch of the laboratory scale electrolytic cell.

with small additions of free alloy, an electrical connection rod, and an interior conducting rod. Both the alloy coating on the shell interior and the free alloy in the pre-densified core material serve to improve the bonding characteristics of the anode core and thus increase the electrical performance of the anode.

Magnesium cell testing of these two anodes met a premature end (One anode lasted 9 days while the second anode lasted only 3 days) when both anodes failed due to the formation of a small hole in the ceramic shell. These anode lifetimes are significantly less than the goal of 30 days. 


\section{Anode Failure Mode And Proposed Mechanism}

The observed anode failure mode is the formation of a small hole in the protective ceramic shell. It is thought that once a hole forms and molten salts enter the anode interior, the operating voltage increases dramatically and the anode interior core is rapidly corroded/dissolved, effectively destroying the anode.

There are three basic potential causes for the onset of failure of the anode during testing;

- Chemical attack

- Physical flaws or cracks in the ceramic

- Electrical attack in the form of ohmic heating.

One theory explaining the formation of the small hole failure mechanism from electrical attack in the form of ohmic heating is depicted in Figure 23. This theory proposes that the point contact between the core granules and the ceramic shell would result in localized areas of relatively high current density. The localized ohmic heating or "hot spots" could in turn result in accelerated wear. Previous work has shown that the corrosion properties of the ceramic shell degrade at temperatures above $800^{\circ} \mathrm{C}$. These "hot spots" are isolated areas of elevated temperature and thus high wear that would result in the formation of the small hole failure.

To address the potential ohmic heating of the anode shell, design modifications were made to the shell. Along with enhancing the physical bond between the core to the ceramic shell, the alloy coating on the shell interior has the added purpose of distributing the current from the granular core to the anode shell. In one tested design modification, the thickness of this alloy coating was increased from $\sim 0.2 \mathrm{~mm}$ to $\sim 0.5 \mathrm{~mm}$. This anode was tested in the lab scale magnesium cell. This anode lasted only 5 days and failed by the same small hole failure mode. 


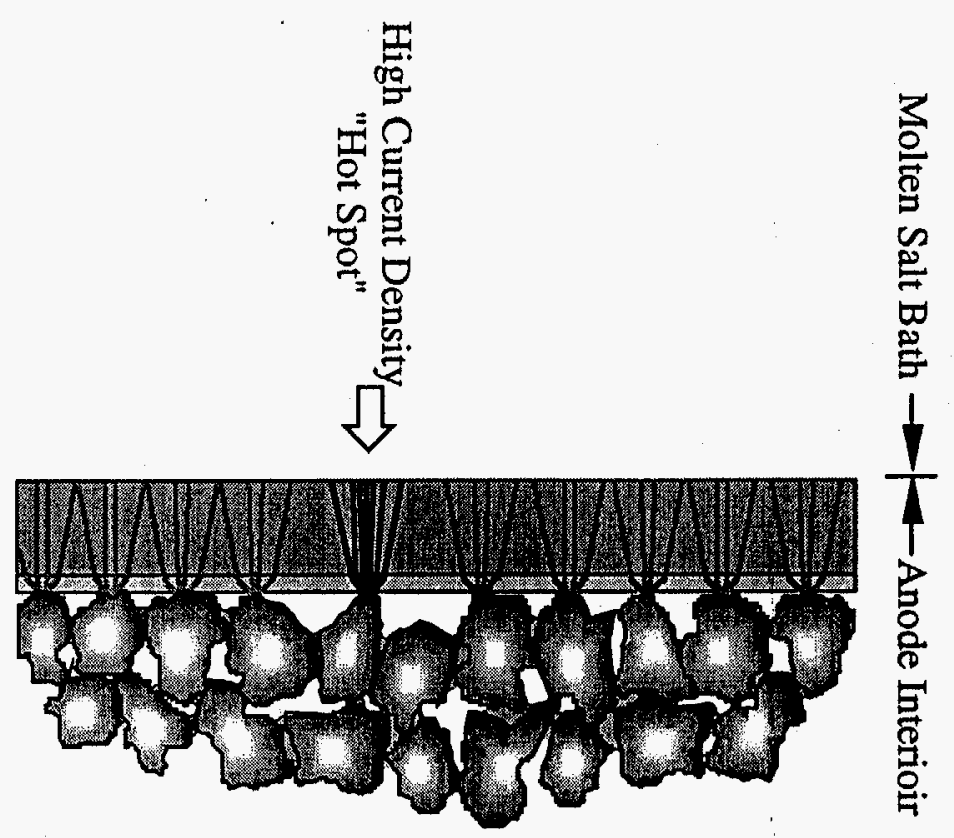




\section{Affect Of Furnace Atmosphere On Dopant Solubility}

Accelerated chemical attack of the ceramic can also cause premature failure of the anode during testing. To investigate the likelihood that an accelerated chemical attack is causing the anode failure, the chemistry of the ceramic was investigated in depth. When heated to the sintering temperature of $-1300^{\circ} \mathrm{C}$, the $\mathrm{Nb}_{2} \mathrm{O}_{5}$ doped $\mathrm{TiO}_{2}$ ceramic material forms a solid solution which has the unique property of being electrically conducting. This solid solution has the rutile crystal structure of pure $\mathrm{TiO}_{2}$ but with oxygen deficiencies which result in its electrical properties. When this shell material is subjected to a heat treatment step corresponding to the filling process step, the $\mathrm{Nb}_{2} \mathrm{O}_{5}$ dopant can precipitate out of the solid solution and migrate to the grain boundaries. During magnesium cell . testing, these dopant enriched grain boundaries have been shown to be attacked by the corrosive magnesium cell atmosphere resulting in anode failure.

Current theory of diffusion and electrical conductivity in oxygen deficient binary oxides predicts that in an oxygen deficient solid solution like ours, the diffusion rate of the dopant can be significantly affected by the furnace atmosphere. 6 Subjecting the ceramic to a oxygen deficient or reducing furnace atmosphere may cause the dopant to precipitate out of the solid solution. This precipitation has been seen in our ceramic anode shells and the reduced corrosion properties of our anodes have been attributed to this occurrence.

Previous attempts at controlling this precipitation have centered around switching the dopant species from $\mathrm{Ta}_{2} \mathrm{O}_{5}$ to $\mathrm{Nb}_{2} \mathrm{O}_{5}$ and then reducing the dopant concentration from 5 mole $\%$ to 3 mole $\% .7$ With our new understanding of the possible affect of furnace atmosphere on the dopant solubility, the viability of performing all of the anode fabrication heat treatment processes in an air atmosphere was evaluated. The fabrication of the anode has three heat treatment steps. The first step is the sintering of the ceramic shell in a forced air furnace. The second step is an alloy coating process where a titanium-copper alloy is bonded to the shell interior. The final step is to melt a conducting titanium based cermet core inside the ceramic shell. Due to the reactive nature of titanium alloys, the coating and filling steps had previously been performed in an inert gas atmosphere or under vacuum. We found that with modifications to our coating and filling procedures and minor material changes, anodes with good electrical and physical properties could be fabricated with only slight modifications to existing equipment.

Figures 24 and 25 show a comparison of SEM micrographs of the ceramic shells taken from anodes that have been fabricated in a reducing atmosphere and one that was 


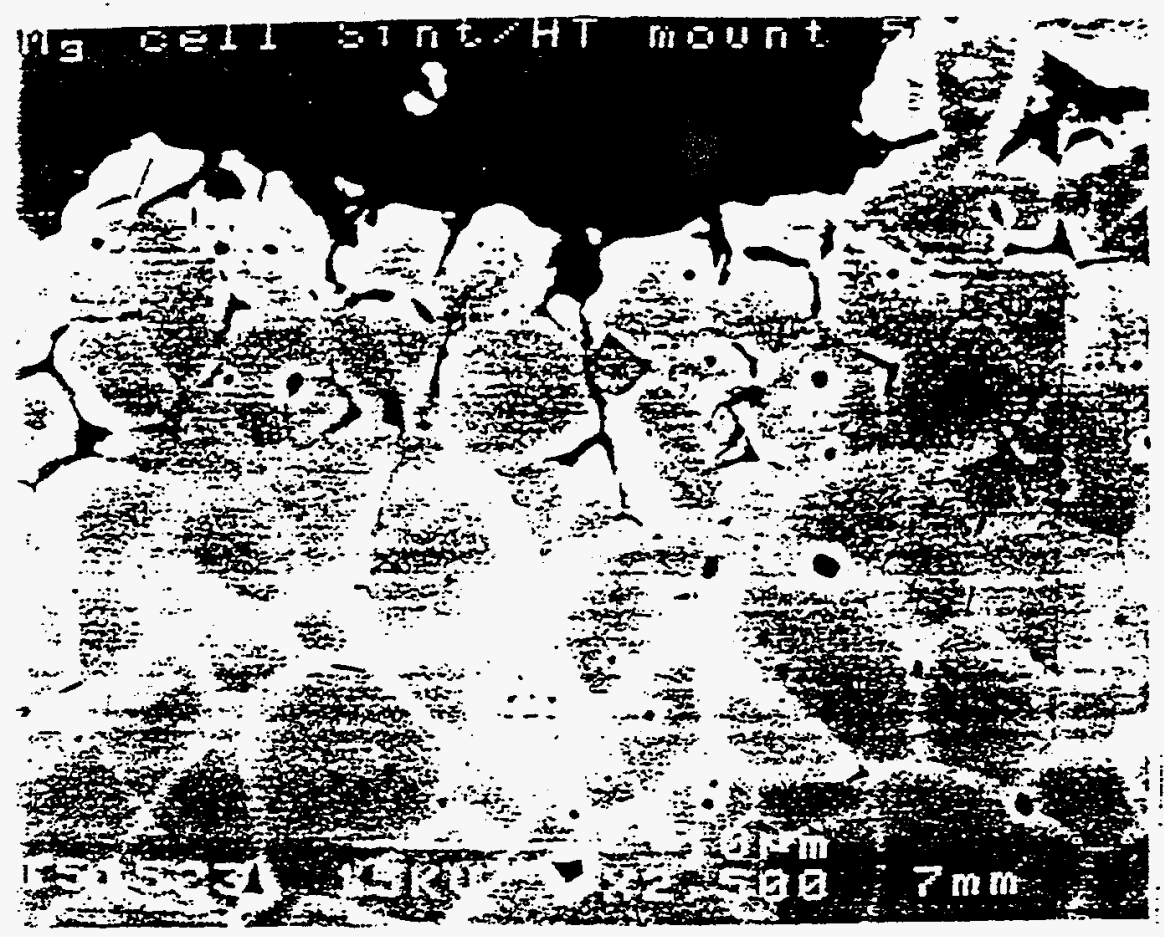

Figure 23, SEM micrograph of the ceramic shell fabricated in a reducing atmosphere.

(Top of micrograph is the outside edge of the ceramic shell)

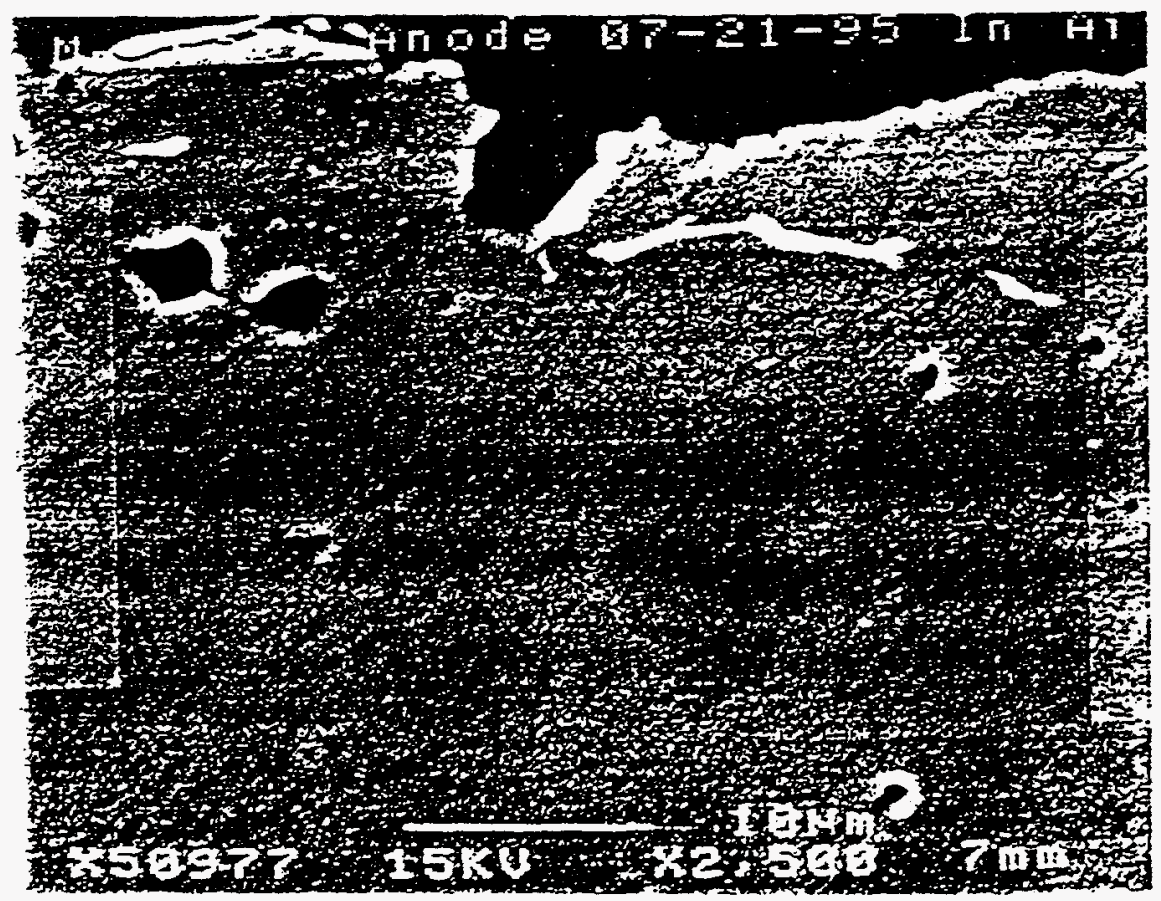

Figure 25, SEM micrograph of the ceramic shell fabricated entirely in an air atmosphere.

(Top of micrograph is the outside edge of the ceramic shell) 
made in an entirely air atmosphere. The anode fabricated in the reducing atmosphere shows grain boundary enrichment of the $\mathrm{Nb}_{2} \mathrm{O}_{5}$ dopant (shown as the lighter phase in the micrograph) and void formation at the grain boundaries. This is compared to the micrograph of the anode fabricated entirely in an air atmosphere that shows no void formation or light phase at the grain boundaries that would correspond with grain boundary enrichment. This achievement marks further refinement of the final ceramic composition that should increase the corrosion resistance of the ceramic anode to the aggressive magnesium cell environment.

\section{Ceramic Quality Impact on Corrosion Failure}

It has been observed that the preferential etching of the ceramic dopant at the grain boundaries was the primary bulk material corrosion mechanism. Several processing . changes were made to minimize and delay the onset of this form of corrosion (i.e. anode fabrication atmosphere modification). This achievement should increase the anode's bulk corrosion resistance properties. Unfortunately, through magnesium cell testing, the bulk' material corrosion of the anode was unexpectedly found not to be the lifetime limiting wear property. Inspection of failed anodes revealed that isolated, pitting type corrosion may be causing the premature anode failure. It also appeared that these isolated severe corrosion areas may be related to the presence of small imperfections in the ceramic shell.

With great confidence, an anode fabricated entirely in an air atmosphere was tested in the laboratory scale magnesium cell. Despite having excellent electrical properties, the anode failed prematurely after only 9 days in the magnesium cell. Fortunately, this test was stopped shortly after failure preserving much of the pre-failure corrosion evidence. In the past, all anodes had failed during non-work hours and thus much of the evidence pertaining to the onset of failure was obscured by extensive post failure corrosion. In this test, the anode was rescued before significant post failure corrosion had occurred.

For this anode test, the test was halted due to the observation of a gradual rise in the cell operating voltage. In lab scale, magnesium cell tests, the cell load is held at a constant $10 \mathrm{amps}$ (except for weekends when the amperage is dropped to $1 \mathrm{amp}$ ) resulting in an anodic current density of approximately 2 amps per square inch. The voltage is allowed to change or float to maintain the controlled amperage. It was found that during the final 16 hours of operation the voltage began to increase from a constant 3.5 volts to 7.5 volts at which time the test was terminated. When the anode was removed from the cell, there were several areas where evidence of the failure mechanism were still intact. 
Because of the evidence of pre-failure corrosion structures, the anode was subjected to intense analytical tests. The anode was analyzed by secondary electron imaging (SEI), backscattered electron imaging (BEI), energy dispersive $x$-ray spectroscopy (EDS), and wavelength dispersive $x$-ray spectroscopy (WDS) elemental maps. Figure 26 presents a series of SEI micrographs showing a crack in the anode shell. Along this crack are irregularly spaced corrosion areas. These corrosions areas appear to be isolated high corrosion rate regions similar to pitting corrosion in metals.

Figure 27 shows a cross-section of another pitting type corrosion area but this time on the interior of the anode shell. This pit appears to coincide with a pre-existing surface crack. This surface flaw is most likely an artifact from the ceramic forming process. Similar greenware flaws of this type have been seen in other ceramic shells. ${ }^{8}$ This interior corrosion indicates that the molten salts of the magnesium cell were present inside the anode with enough time to erode or pit the interior surface. It is our hypothesis that these molten salts gained entrance to the anode interior through small cracks in the protective ceramic shell. These cracks would have to be formed during testing in order to pass the pre-test inspection and small enough to escape the periodic anode inspection during operation. 


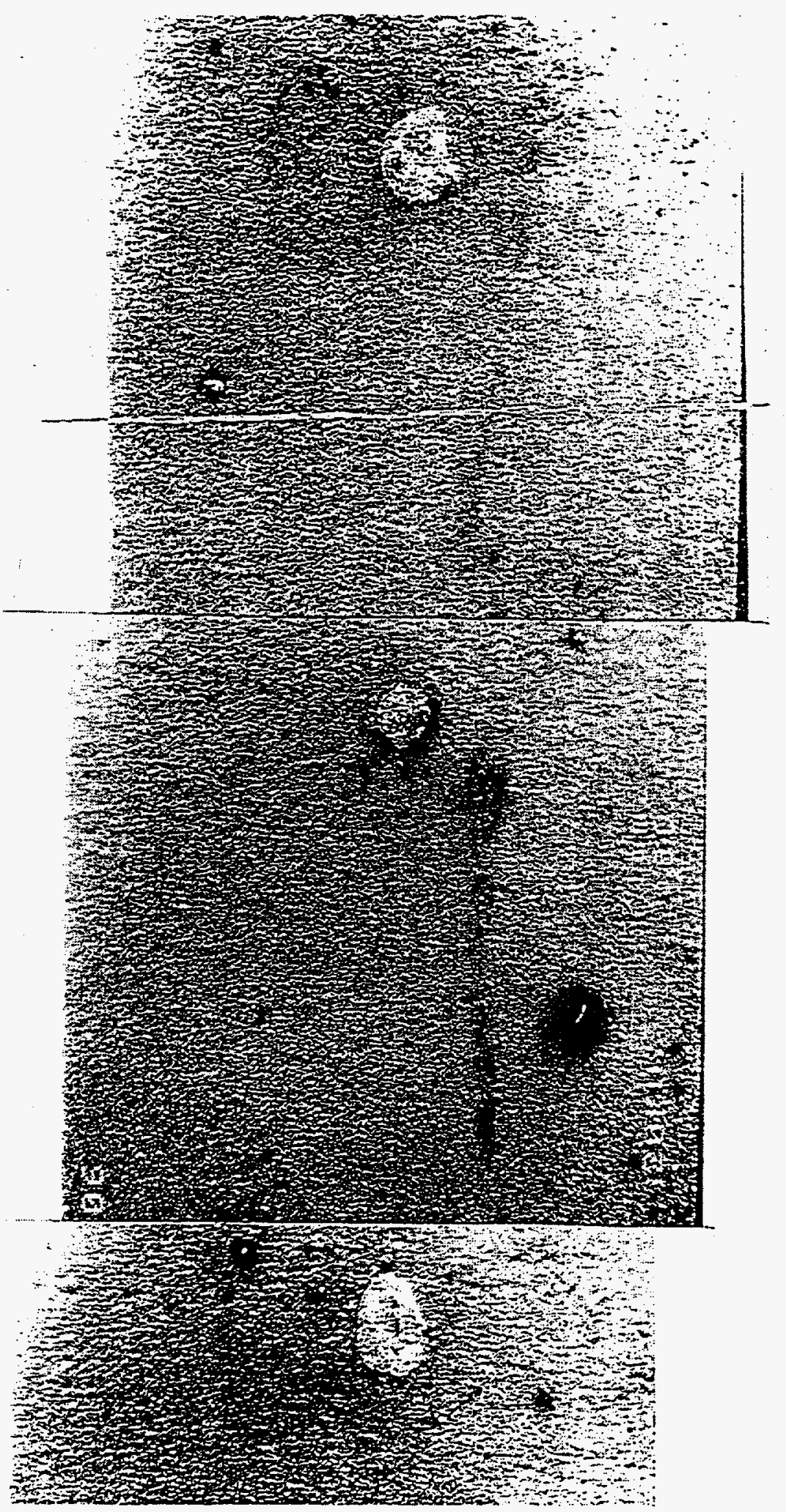

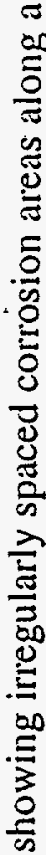

录

$0 \frac{0}{0}$

.

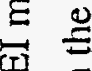

㱐 $\Xi$

广

क

ஸे

$\underbrace{0}_{0}$ 


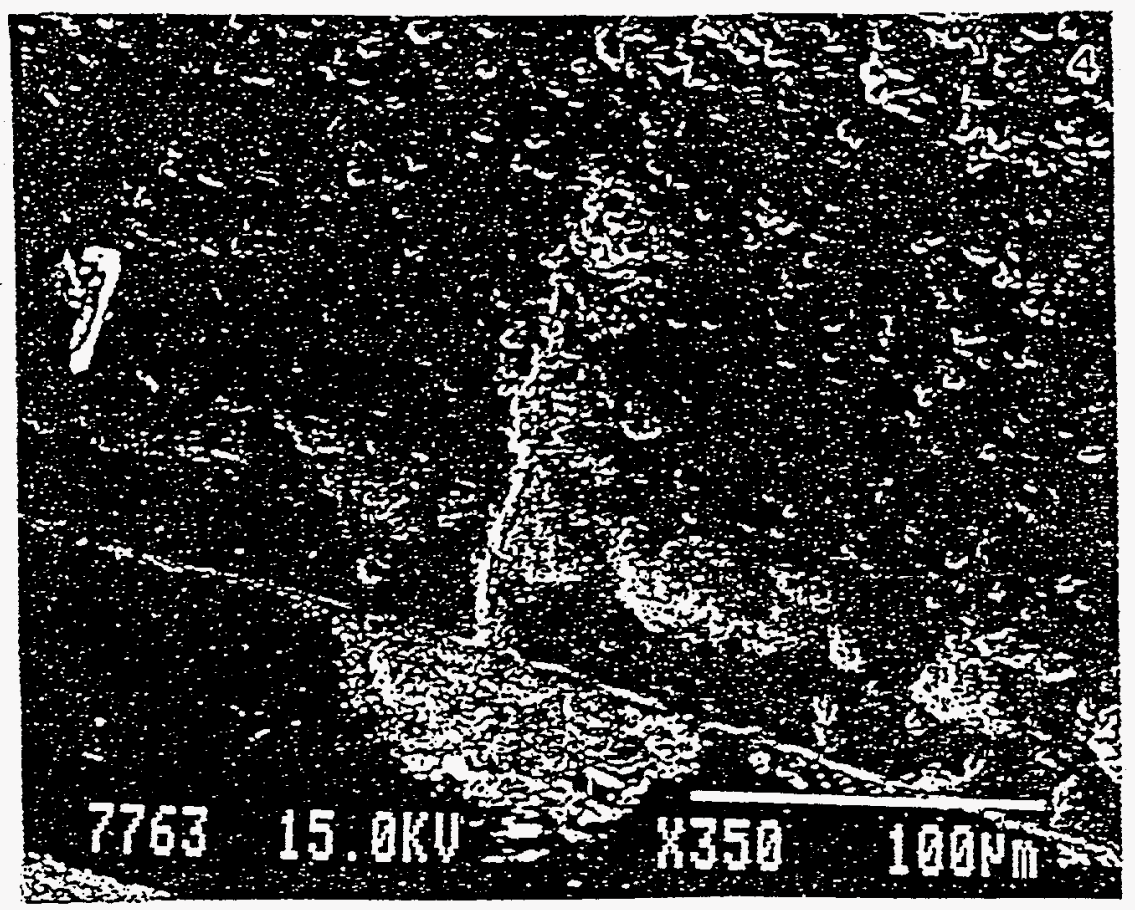

Figure 27. Cross-section of pitting type corrosion area.

\section{Short Duration Anode Testing}

To gather additional information about the onset of failure, two short duration magnesium cell tests were conducted. The first test was a four day operational test. The anode inspection after this short test revealed that the molten salts of the magnesium cell bath had reached the anode interior. The voltage history for this test showed no indication of when the salts might have entered the anode. It is thought that the presence of a conductive liquid inside the porous core of the anode would at least initially increase the electrical performance of the anode reducing the operating voltage for a short period before interior corrosion becomes severe. Also, no clear evidence of a crack in the ceramic shell was evident.

A two day test was conducted in an attempt to catch clear evidence of the onset of anode failure before the molten salts reach the anode interior. Once again, there were no fluctuations in the operating voltage during the two day test. However, post-mortem analysis showed that this anode also had molten salts inside the anode. During cooling of the anode, a -2 inch, rust colored line appeared along one side of the anode running along the long axis of the anode. Further inspection revealed that this line was in fact a hair-line 


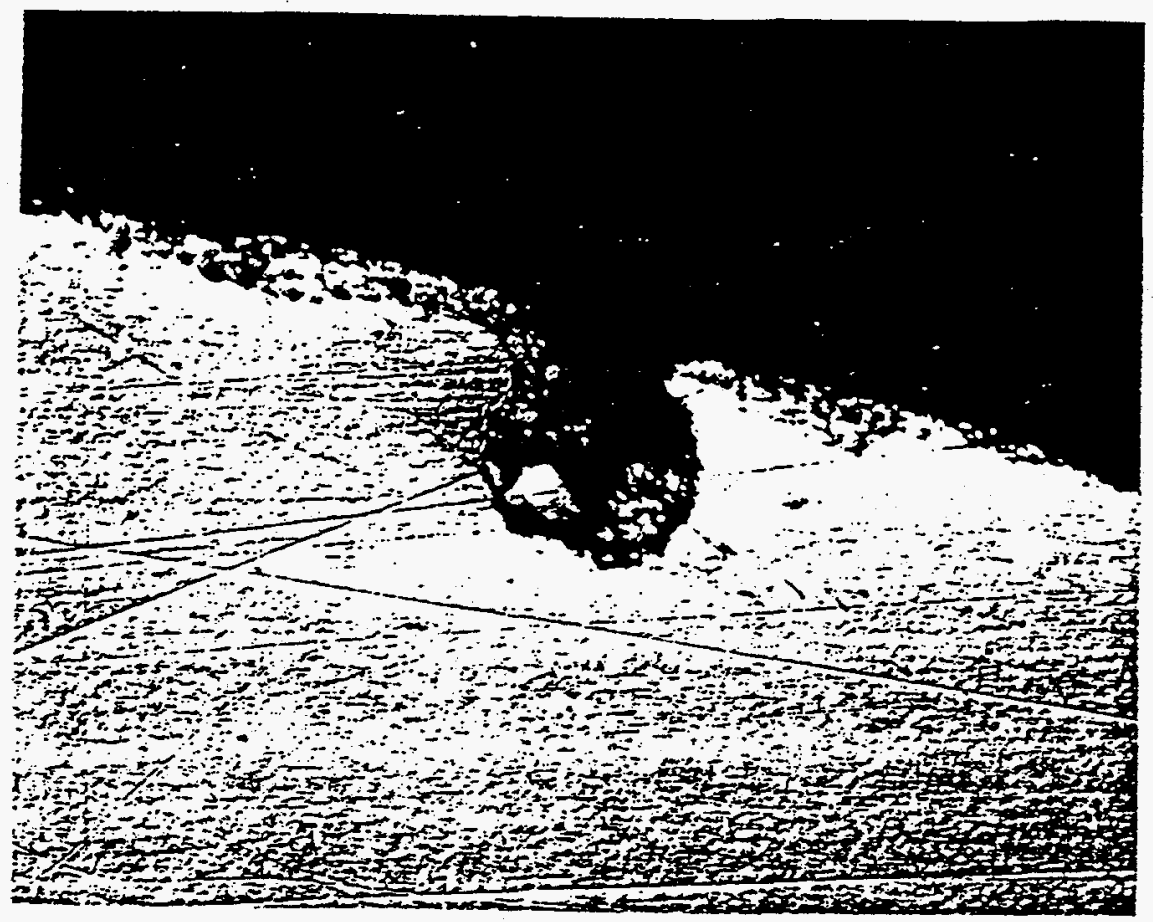

Figure 28. Optical micrograph of the pinhole defect.

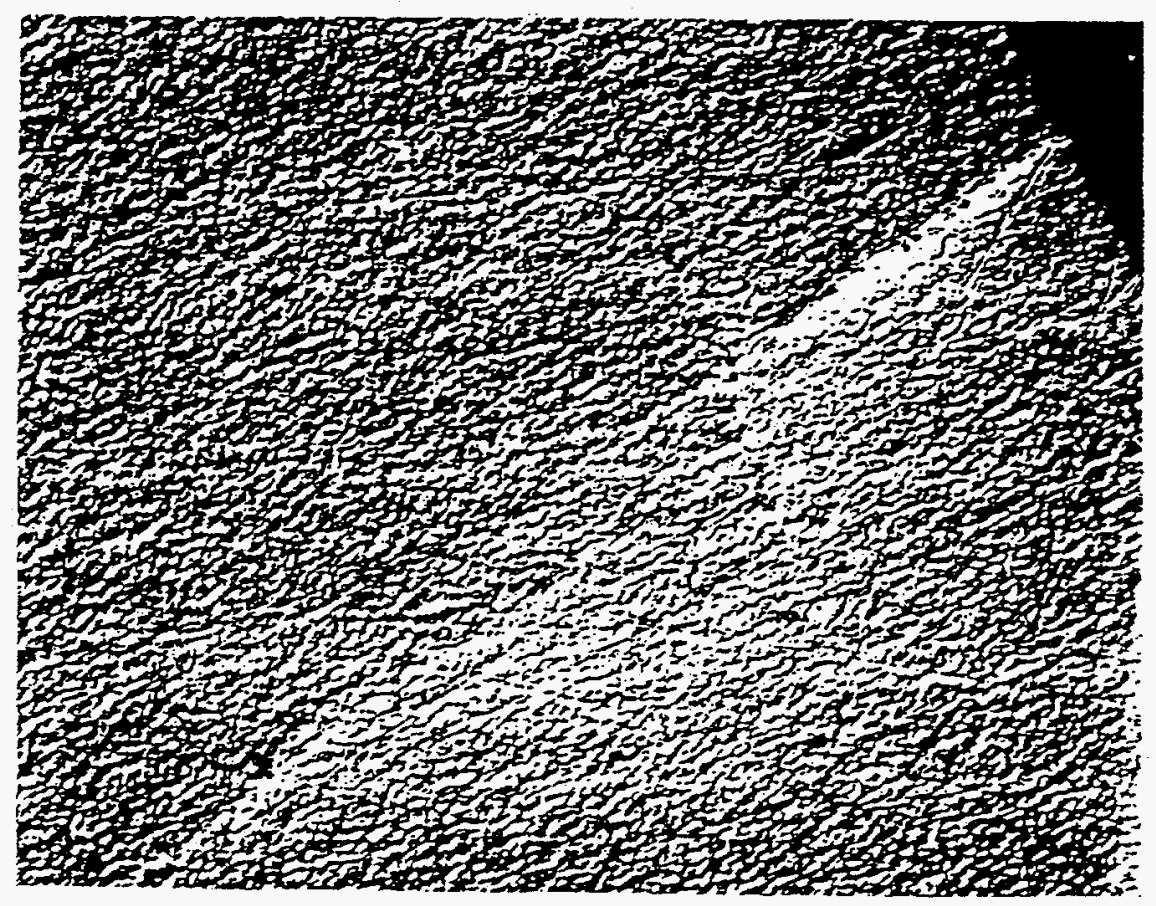

Figure 29. Optical micrograph of a heeled crack that occurred in the green state 


\section{Anode Lifetime Testing}

With improved fabricating procedures and an increased understanding of the anode corrosion mechanisms, there was renewed confidence in achieving the 30 day lifetime magnesium cell tests. With these recent technical strides, the direction of the research team has focused more tightly on reaching the project's testing milestones. During all steps of the fabrication process, these anodes are subjected to numerous quality control nondestructive evaluation (NDE) such as: fluorescent dye penetrant tests, optical microscopy, and room temperature resistivity measurements.

After arriving at the Dow's Inorganic Research Laboratory in Freeport, Texas, the first of these improved anodes were tested at an operating current of 6 amps. This anode achieved the milestone of surviving 30 days of continuous operation in the lab scale . magnesium cell. The anode was removed from the test cell after 32 days while still intact.

A second anode of similar design was tested at the same operating conditions. This anode also reached the 30 day lifetime goal. The anode was removed from the cell after 34 days of testing. This anode was also intact and had the appearance of being able to survive for significantly longer. Both of these tests were terminated so that confirmation tests could be run and the 6 anode, 30 day test milestone could be meet within the tight program schedule. Both of these anode test fully meet the requirements outlined in the testing plan and thus are valid, successful tests.

\section{Wear Measurements And Procedures}

As the anode lifetime gets longer, it becomes possible and important to measure the anode wear rate to determine the expected production anode lifetime. We have found that determining the wear rate of the anode is not a trivial matter. Simple displacement measurements are not accurate due to the formation of hard deposits on the ceramic surface during cool down. In removing these deposits, some of the ceramic shell is also removed or chipped away making the displacement measurements inaccurate. Direct diameter measurements of the anode before and after testing have also proven unreliable. The ceramic anodes tend to be slightly out of round making the measurement of the very small wear numbers difficult even when attempting to measure at the exact location on the anode before and after cell testing.

A microscopic technique has been developed that has shown to produce repeatable and reasonable wear numbers. The technique utilizes a low magnification optical 
microscope with an attached digital camera. The anode is first mounted on a X-Y micromanipulator platform. A straight edge is then mounted on the platform in close proximity and parallel to the anode. A series of digital images are then taken and printed on a 8 " by $5 "$ paper. Enough pictures are taken to cover an approximately 1.5 inch area that traverses the working and non-working portion on the anode. The pictures can then be re-assembled using the photographed straight edge as a guide. A large straight edge can then be used to reveal the amount of wear by comparing the deviation of the working area surface from the interpolated reference line taken from the non-working surface. Wear rates for both 30 day, 6 amp magnesium cell test anodes have been measured. These wear numbers are shown in table IV.

Table IV. Anode wear in laboratory scale magnesium cell testing

\begin{tabular}{|lrlll|}
\hline $\begin{array}{l}\text { Anode ID } \\
\text { Number }\end{array}$ & $\begin{array}{l}\text { Operating } \\
\text { Amperage }\end{array}$ & $\begin{array}{l}\text { Test } \\
\text { Duration }\end{array}$ & $\begin{array}{l}\text { Wear } \\
(\mathrm{mm} / \mathrm{yr})\end{array}$ & $\begin{array}{l}\text { Wear } \\
(\mu \mathrm{m} / \text { Amp-hr })\end{array}$ \\
\hline $9301739 P 97$ & 6 Amps & 32 days & $2.1 \mathrm{~mm} / \mathrm{yr}$ & $0.073 \mu \mathrm{m} / \mathrm{Amp}-\mathrm{hr}$ \\
$9301739 \mathrm{P100}$ & 6 Amps & 34 days & $1.5 \mathrm{~mm} / \mathrm{yr}$ & $\mathbf{0 . 0 7 1} \mu \mathrm{m} / \mathrm{Amp}-\mathrm{hr}$ \\
\hline
\end{tabular}

These are the first reliable wear numbers obtained on the niobium doped titanium dioxide ceramic anode. The measured wear for this niobium doped material compares favorably with the $3.3 \mathrm{~mm} / \mathrm{yr}$ wear number reported for the tantalum doped ceramic anodes ${ }^{l}$ that were being developed and tested in the first phase of this cooperative agreement. Recall that the raw material change from tantalum pentoxide to niobium pentoxide was prompted by a rough economic evaluation of the price to manufacture the full scale anode. It was found that the dopant switch would result in a $\sim 60 \%$ reduction in the total raw material cost of the assembled anode. Electron probe and transmission electron microscopy revealed that the dopant material change also appeared to reduce the precipitation of the dopant to the grain boundaries. This dopant migration was identified as a major anode wear mechanism ${ }^{2}$. 


\section{Preparing For Higher Current Density Tests}

The laboratory scale magnesium cell testing plan included in the program proposal defines the cell operating range of 5 to 20 amps current load on the anode. After the two successful lifetime tests at a 6 amp operating amperage, the decision was made that higher amperage tests would be valuable in assessing the expected performance in the production cell that operate at higher current densities. However, due to the anode and cathode geometry differences, direct comparison between the lab scale test results and the expected production cell performance can not be made. This change in testing procedure was also motivated by the loss of Government funding for Phase III of the cooperative agreement. Without Government assistance, the Dow's magnesium business decided that the technical risk associated with scaling-up and implementing the ceramic anode into production would need to be minimized if the project was going to proceed without Government assistance. To minimize the technical risk, higher operating current tests would be necessary to determine the anode's sensitivity to operating current range or robustness.

To start evaluating the anode lifetime sensitivity to operating current density, an anode was tested at the higher operating current of 10 amps. This anode had a similar design to that of the two anodes that had successfully survived the 30 day test running at 6 amps. This anode failed after 24 days of operation. While this anode did not reach the 30 lifetime goal, 24 days of operation was still longer than previous tests on 'un-improved' anodes.

It was felt that ohmic heating and the cathode geometry may have impacted this test. This brings up the question of the effect of cell geometry on the effective current density that the anode experiences. Referring back to the lab scale magnesium cell's geometry pictured in figure 21 , the cylindrical anode is located in a relatively large bath of molten salts along with the rectangular, flat steel plate cathode. Comparing this lab scale cell to the production cell, shown in figure 30 , the difference in cathode design and relative molten salt bath volumes between the two cell geometries is evident.

The lab scale cathode design is a concern due to the possibility of preferential wear of the anode directly facing the cathode. In the lower current tests, the anode appears to be wearing evenly about the entire circumference of the anode. 


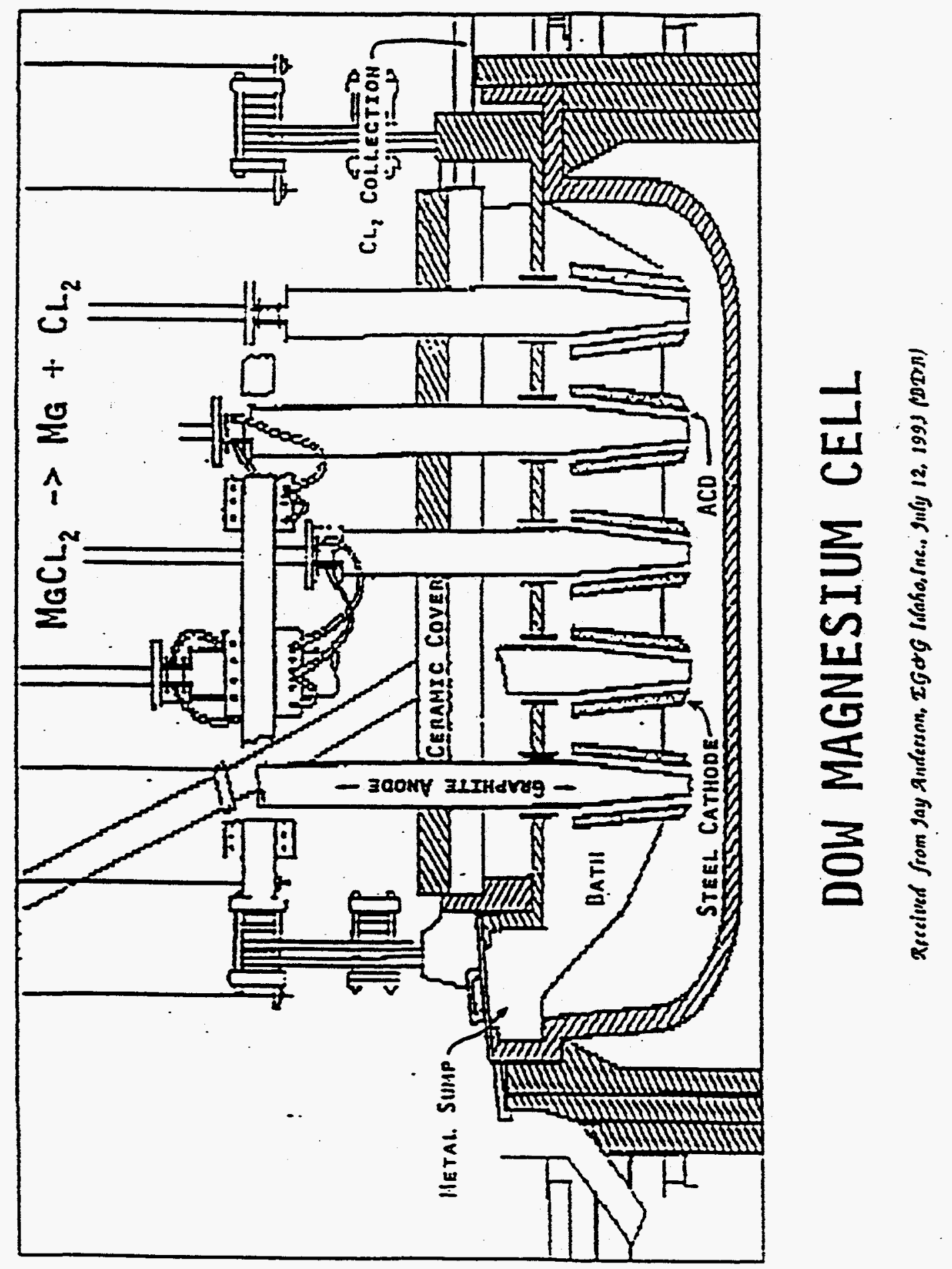

Figure 30. Production cell geometry sketch 
The even wear can be attributed to the highly conductive molten salt bath. However, at higher operating current, there may be a concentration of the current density on the anode facing the cathode causing increased wear in that region. After the completion of the higher current density tests, the anode was inspected for this type of wear pattern. If found to be the cause of the anode failure, the fact that this unsymmetrical wear is an artifact of the test cell geometry and will not be present in the full scale magnesium cell will have to be considered.

The second disparity between the lab scale cell and the production cell is the relative molten salt bath volumes compared to the anode surface area. This is a significant difference due to the function of ohmic heating in the production cell. At full capacity operation, the production cell is heated solely by the ohmic heating of the anodes and electrolyte. In this way, the temperature of the molten salt bath is maintained in a very uniform manner. In contrast, the lab scale cell is heated by surrounding heating elements due to the larger relative bath volume to the anode surface area. The bath temperature is controlled via a thermocouple in the bath. Unfortunately, this control scheme does not directly reflect the temperature at the anode surface where additional heat is being added to the system through ohmic heating. This is a concern because modest $\left(-80^{\circ} \mathrm{C}\right)$ increases to the molten salt bath result in accelerated corrosion of the ceramic anodes ${ }^{1}$. Anode to be tested at 20 amps were modified to incorporate an imbedded thermocouple to evaluate the magnitude of this temperature differential that may arise from ohmic heating.

\section{High Current Density Tests}

Two extremely high quality anodes were fabricated, subjected to extensive nondestructive analysis, and then sent to Texas for laboratory scale magnesium testing at the high operating current of 20 amps. These anodes had a similar design to that of the two anodes that had successfully survived the 30 day test running at 6 amps but also included the imbedded thermocouple to detect any ohmic heating. During the testing, the temperature recorded by the imbedded thermocouple was consistently $\sim 10^{\circ} \mathrm{C}$ lower than the surrounding molten salt bath. This indicates that any ohmic heating that was occurring was being overwhelmed by the cooling from the exposed top section of the anode that protrudes out of the magnesium cell into the cooler atmosphere of the surrounding laboratory fume hood. Simply put, the anode is acting like a large cooling fin. Thus, the proposed lailure mechanism of gross ohmic heating has been disproved. This first anode tested at 20 amps operating current failed after only 6 days of operation. The second anode was then tested at the same operating conditions. This anode also showed the cooler 
temperature at the anode interior compare to the cell bath temperature. This second anode tested at 20 amps operating current failed after only 3 days of operation. Both of these anodes failed by the formation of pitting type corrosion.

The above results reflect a strong dependence between corrosion resistance and operating current. Post mortem analysis revealed that neither of the anodes showed significant asymmetric wear on the face nearest the cathode. This indicates that the geometry effect of the laboratory scale magnesium cell does not have as large and effect on wear as previously thought. The theory of gross ohmic heating was also discounted by the thermal couple data. However, the thermal couple data does not rule out the presence of isolated, small temperature rises caused by various sources could result in the accelerated wear seen. Microscopic imperfections in the shell could be exploited by the very mobile molten salts producing a highly conductive route for energy flow, acting almost like a lightning rod across the ceramic. Much attention throughout the program has been directed at minimizing these types of microscopic flaws. Unfortunately, higher current densities appear to exploit even the smallest of flaw populations. This raises some hard questions about the ceramic anode robustness with respect to both sensitivity to operating conditions and to tolerance of even small flaw population in the ceramic shell. These issues present significant challenges to overcome before anode implementation.

\section{Scale-up Partner Interactions}

Identifying a partner to scale-up the anode technology was an important task during the second phase of the cooperative agreement. Once identified, the scale-up partner would need to be brought up to speed on the technology. Ipsen Ceramics was selected to fabricate a full scale ceramic anode for magnesium metal production as a subcontractor in phase III of the program base on their production and development capabilities. Figure 31 is a sketch of the proposed full scale anode. Ipsen was identified as a potential partner along with three other companies. Ipsen Ceramic's initial selection was made due to their advertised ceramic products of similar large dimension. Ipsen ceramics is a wholly owned company of Abar Ipsen Industries, (a several billion dollar sales company). Ipsen ceramics itself, is very small reporting 1993 sales of $-3.6 \mathrm{MM}$. 


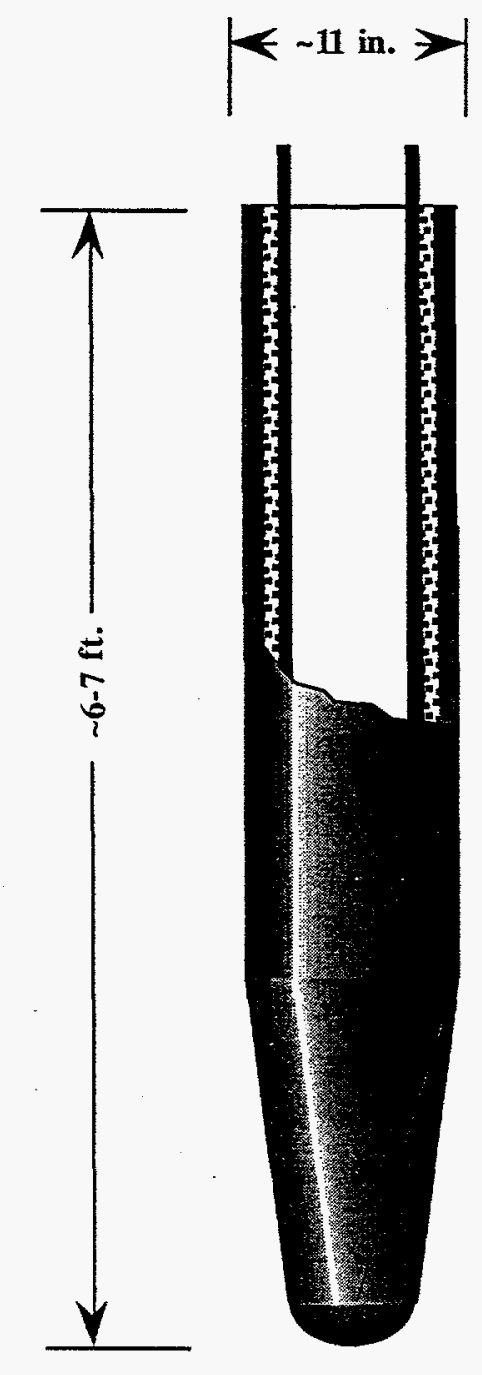

Figure 31. Full scale anode sketch

Some of the key capabilities we were looking for in a scale-up partner are the following:

- Ability to cast large, closed end tubes

- Ability to sinter large tubes

- Familiarity with casting fine particle size ceramics

- Developmental facilities

- Good engineering support

- Desire to work on project

- Flexibility to consider fabricating entire anode

Ipsen Ceramics was found to have the production capability along with all of the above capabilities except a slight weakness in developmental facilities 
To addresses critical scale-up issues, a joint development project was initiated with Ipsen Ceramics. This joint program was designed to include a general evaluation of the quality of Ipsen's large ceramic parts along with a direct lab scale anode shell comparison. For the lab scale shell comparison, Ipsen made casting molds with the lab scale anode mandrel and then cast and sintered three shells with their similar product, 995 Alumina. These anodes where then delivered to Midland for flaw testing. The second stage was then to cast and sinter 2-3 shells with slip provided by Dow Chemical to provide a direct comparison to shells produced by Dow Chemical. The final task was to mill, cast, and sinter the Dow powder formulation with Ipsen's standard binder system. These anodes where also sent back to Dow for evaluation.

Along with this joint development program, Ipsen delivered a large slip cast closed end tube for Dow to evaluate for casting defect increases to expect during scale-up. Results from optical microscopy analysis reveal that Ipsen's large tube does have casting defects similar to which we had seen and deemed unacceptable in our own cast parts cast in the early stages of the program. Once the developmental anodes were received from Ipsen, they were subjected to dye penetrant testing and also sectioned, mounted and polished for micrographic analysis. During this analysis, we found that the shell produced by Ipsen had a significant amount of exterior surface bubbles or pinholes casting defects. However, there shells did not have any greenware drying defects.

A working meeting was arranged in which the entire casting and sintering processes was reviewed at Ipsen Ceramics. The outcome of this meeting was the successful transfer of technology associated with the handling of the anode shells. During this technology transfer several key processing steps were identified as direct causes of the defects that were seen in the ceramic shells. Fortunately, these exact processing problems had already been dealt with and solved in the development work performed in Midland.

Ipsen Ceramic will use these processing improvements in completing the third task in our joint development program. In the third task where Ipsen milled, cast, and sintered the Dow powder formulation with their standard binder system and processing equipment. These anodes shells incorporating the Dow technology showed marked improvement. 


\section{Summary}

Significant steps have been made in development of a dimensionally stable ceramic anode to be used in magnesium metal production. A stable anode would allow optimization of the spacing between anode and cathode yielding significant energy savings of per pound of magnesium produced. In addition, the currently used graphite anodes are consumed during electrolysis at a cost of up to $\$ 3.3 \mathrm{MM} / \mathrm{yr}$. There is also considerable projected labor savings from the elimination of the need to reposition the anodes to maintain the anode's electrical efficiency. Not having to adjust the anode would allow better sealing at the furnace/anode interface for substantial environmental benefits.

Strides have been made in the fabrication of the ceramic anode with the invention and development of a novel pre-densified composite core material which uses the SHS processing route. By using this pre-densified composite material with standard anode . fabrication procedures, completely filled, crack free anodes can be produced. This SHS core material has the unique properties of providing a strong bond with the ceramic while having a good thermal expansion match with the shell ceramic. The ceramic shell processing techniques have also been addressed in painstaking detail. The early laboratory scale magnesium cell testing revealed that the quality of the ceramic shell used for the protective barrier against the corrosive cell environment was critical to the survival of the anode. Though the course of this project, state of the art slip casting techniques were used and advanced in the pursuit of a virtually flaw free ceramic anode shell. A program was initiated with our designated scale-up partner to transfer our slip casting technology developed in the program and also to identify the challenges that might be faced during sciale-up.

The testing goal for Phase II of the cooperative agreement was to demonstrate six anodes surviving a 30 day test lifetime with acceptable wear rates and electrical performance in a laboratory scale magnesium cell test. During this program, two successive anodes were tested and exceeded the 30 day cell lifetime goal with excellent wear characteristics. Unfortunately, a notification that the Government portion for Phase III funding would not be available to assist in scale-up of the project shifted the testing emphasis to more aggressive laboratory tests to evaluate the technical risk associated with continuing the anode replacement project without Government funding. Anodes tested at the more aggressive, higher amperage testing conditions failed from the formation of pitting type corrosion similar to that seem in metal corrosion. The failure of the anode to survive the more aggressive cell tests revealed that the ceramic anode had a rather narrow operating region. This lack of robustness of the dimensionally stable ceramic anode resulted in the Dow Chemical Company's Magnesium Business to make the decision not to continue the project 
without continued Government support.

62 


\section{References}

1. a. A. L. Finley, S. F. Spangenberg, and D. J. Searson, "Low Wear Magnesium Cell Anodes," CRI 774569, Lab. Code NEI-447, June 10, 1977.

b. J. H. Muhs, "Conductive Molten Metal Cores for Ceramic Magnesium Anodes," CRI 780721, Lab. Code NEI-462, December 30, 1977.

c. A. L. Finley and D. V. Livingston, "Ceramic Magnesium Cell Anode," CRI 785929, Lab. Code NEI-488, August 10, 1978.

d. A. L. Finley, D. J. Searson, and J. Amrozowicz, "Initial Lifetime Studies for Ceramic Magnesium Cell Anodes," CRI 811351, Lab. Code NEI-537, April 6, 1981.

e. A. L. Finley, D. J. Searson, and J. Amrozowicz, "Data Review - Ceramic Anode Lifetime Study," CRI 811596, Lab. Code NEI- 542, May 5, 1981.

f. A. L. Finley, D. J. Searson, and J. Amrozowicz, "Grain Size Reduction in Ceramic Magnesium Cell Anodes," CRI 814204, Lab. Code NEI-557, October 28, 1981.

g. S. F. Spangenberg, A. L. Finley, and D. J. Searson, "Electrolytic Cell and Anode for Molten Salt Electrolysis," U.S. Pat. No. 4370216 (1983).

h. S. F. Spangenberg, A. L. Finley, and'D. J. Searson, "Process and Anode for Molten Salt Electrolysis," U.S. Pat. No. 4448654 (1984).

2. H. Hahn, J. Logas, and R. S. Averback, "Sintering Characteristics of Nanocrystalline $\mathrm{TiO}_{2}$, " J. Mater. Res., 5 [3] 609-14 (1990).

3. H. Wohlfromm, P. Pena, J. S. Moya, and J. Requena, "Slip Casting of $\mathrm{TiO}_{2}$," pp. 1.2111.217, in Euro-Ceramics, Vol. 1, Processing of Ceramics. Edited by G. de With, R. A. Terpatra, and R. Melselaar. Elsevier Applied Science, New York, 1989.

4. L. I. Verba and E. V. Degtyareva, "Rheological and Technolgical Properties of Titanium Dioxide Slips and the Properties of the Castings," Ogneupory, 1978, [3], 28-33. 
5. S. A. Anderson, B. D. Bubaker, M. J. Semer, A. G. Haerle, R. D. Varjian, "Development of an Inert Ceramic Anode to Reduce Energy Consumption in Magnesium Production: Progress Report for 1/1/93 to 12/31/93," GOV-ATAR-94-218, Dec 10, 1994.

6. P. Kofstad, Nonstoichiometry. Diffusion, and Electrical Conductivity in Binary Metal Oxides, John Wiley \& Sons, Inc, New York (1972).

7. S. A. Anderson, et al., "Development Of An Inert Ceramic Anode To Reduce Energy Consumption In Magnesium Production; $2^{\text {nd }}$ Quarter Report" Cooperative Agreement DE-FC07-91 ID13133, July 31, 1995.

8. Dr. Richard Haber, Rutgers Center for Ceramic Research, Private communication, December, 1995. 